The following article is the final draft of the published version.

Masoud Naseri \& Javad Barabady, 2016. On RAM performance of production facilities operating under the Barents Sea harsh environmental conditions, International Journal of System Assurance Engineering and Management, Volume 7, Issue 3, pp. 273-298. http://dx.doi.org/10.1007/s13198-016-0463-x 


\title{
On RAM performance of production facilities operating under the Barents Sea harsh environmental conditions
}

\author{
Masoud Naseri ${ }^{1,2}$, Javad Barabady ${ }^{1}$ \\ ${ }^{1}$ Department of Engineering and Safety, UiT - The Arctic University of Norway, N-9037, Tromsø, Norway \\ ${ }^{2}$ Corresponding author
}

\begin{abstract}
Oil and gas (O\&G) industry is expanding its activities into Arctic offshore, where is characterised with severe operating conditions and less-developed infrastructure. Such conditions affect the reliability, availability, and maintainability (RAM) of offshore O\&G plants, operations, and activities through different scenarios. Plant RAM analysis provides key information for decision-making on, for instance, life-cycle cost management, inventory management, future investments, establishing maintenance policies, and safety-barrier management. Such decisions are of crucial value in Arctic offshore applications due to higher initial and operational costs. Therefore, a thorough evaluation and quantification of the effects of operating conditions on plant RAM performance play a significant role in such decisionmaking processes. In this regard, the aim of this paper is to broadly review and discuss different elements of offshore operating conditions specific to the Barents Sea, and further investigate various effects of such conditions on plant RAM. The present study can provide fundamental information to the academic and industrial sectors involved in the research and development of Arctic offshore O\&G facilities and operations.
\end{abstract}

Key words: Arctic offshore; Barents Sea; reliability, availability, and maintainability; oil and gas; harsh operating conditions.

\section{Introduction}

O\&G industry is expanding its activities into Arctic offshore including the Barents Sea due to the maturity of O\&G resources in normal-climate regions, advancements in Arctic offshore technology, and presence of significant amount of undiscovered petroleum resources in the Arctic, to name but a few (Hasle et al., 2009). A survey conducted by US Geological Survey in 2008 indicates that Arctic resources account for about 22\% of the total undiscovered, technically recoverable resources in the world. More specifically, Arctic resources hold about $13 \%$ of the undiscovered oil, $30 \%$ of the undiscovered natural gas, and $20 \%$ of the undiscovered natural gas liquids in the world. In total, $84 \%$ of Arctic hydrocarbon resources are expected to occur offshore (USGS, 2008).

Total undiscovered conventional and technically recoverable petroleum resources in the Barents Shelf are approximately 11 billion barrels of crude oil, 380 trillion $\mathrm{ft}^{3}$ of natural gas, and 2 billion barrels of natural gas liquids according to the estimations made by US Geological Survey in 2009 (Klett and Gautier, 2009). The Norwegian Barents Sea holds about $30 \%$ of undiscovered O\&G resources of the Norwegian Continental Shelf (Hasle et al., 2009). The first exploration well in the Norwegian Barents Sea was drilled in 1980, which was 
followed by the first discovery in 1981. The major discoveries in this area are Snøhvit (discovered in 1984), Goliat field (discovered in 2000), and Johan Castberg (discovered in 2011), all of which are located in the western Barents Sea as shown in Figure 1a (NPD, 2013). In the Russian Barents Sea, exploration drilling began in the early 1980s. In 1982, the first discovery, which was O\&G, took place in Triassic sandstones on Kolguyev Island in the southeastern Barents Sea (Doré, 1995). As shown in Figure 1b, the major discovered petroleum resources are Shtokman, Ledovoye, Ludlovskoye, Murmanskoye, and Severo-Kildinskoye, all of which contain approximately 3,700 million tons of oil equivalent in total (Moe, 2010; Moe and Rowe, 2008). A summary of petroleum activities and hydrocarbon resources in the Norwegian and Russian Barents is given in (Doré, 1995; Moe, 2010; Moe and Rowe, 2008; Zolotukhin and Gavrilov, 2011).

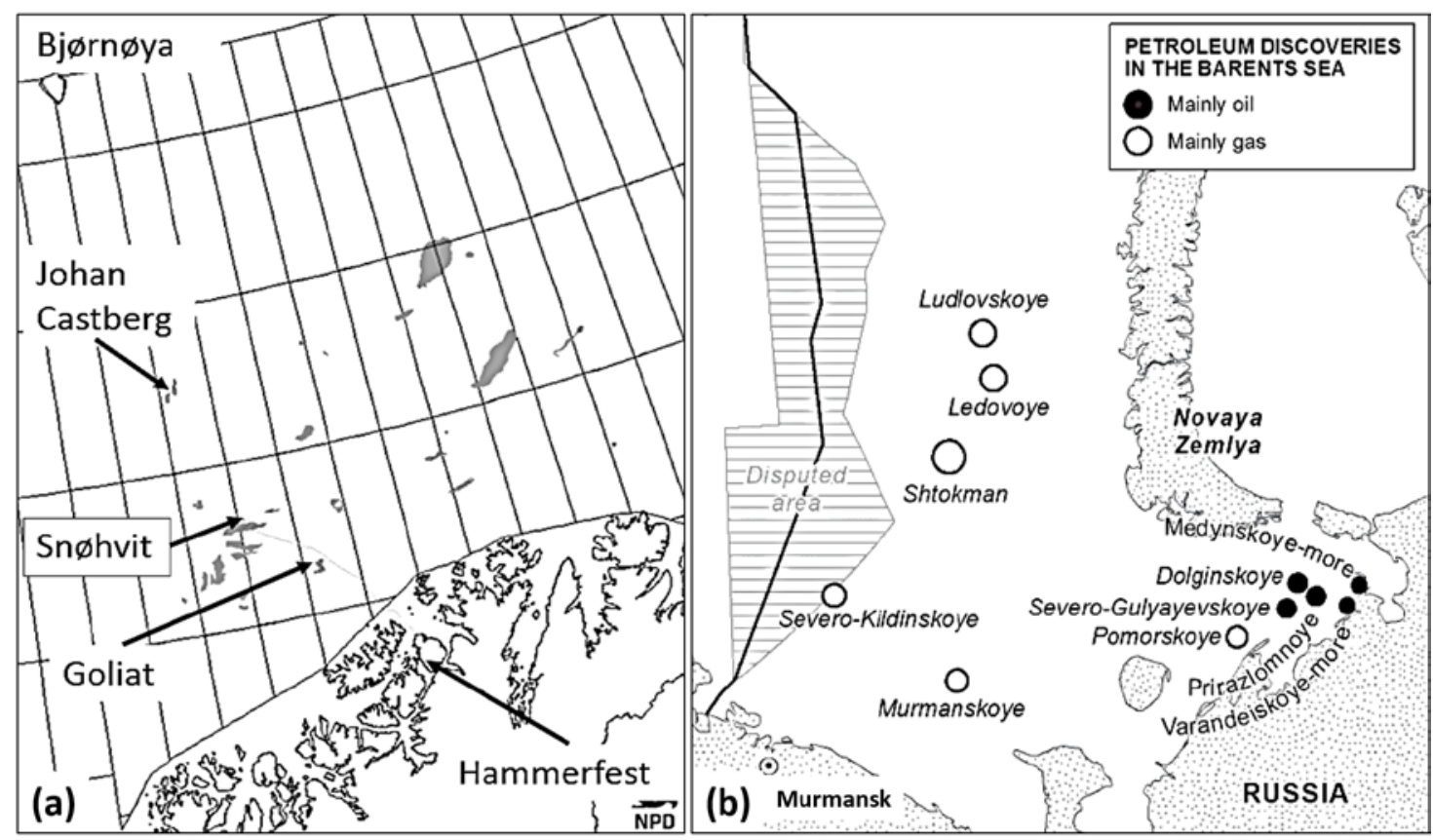

Figure 1. Major O\&G fields in (a) the Norwegian Barents Sea (Source: Norwegian Petroleum Directorate) and (b) the Russian Barents Sea (Moe, 2010)

The Barents Sea is a region with a sensitive environment and less-developed infrastructure. O\&G plants are located in remote offshore locations with harsh weather conditions, presence of sea ice and icebergs, icing events, seasonal darkness, and reduced visibility. Such conditions pose different issues and challenges to the design and operation of O\&G plants and activities in the Barents Sea and thus negatively affect their performance (Barabadi and Markeset, 2011; Gudmestad and Karunakaran, 2012; Naseri et al., 2016; Zhang and Yue, 2011; Zolotukhin and Gavrilov, 2011).

Performance of a plant or an operation can be used as a criterion to judge its ultimate and overall worth. Among other indicators, RAM is a commonly used one to assess the performance of $O \& G$ plants. RAM analysis can be used to determine the engineering integrity in the design of large and complex systems including as $O \& G$ exploitation and production facilities. During operation phase, RAM analysis is used to determine how well a system meets its established requirements. It also provides key input to operation cost-benefit ratio, 
production rate prediction, business continuity, risk and safety barriers assessments, spare parts planning, and emergency plans, for decision-making on field development, future investment strategies, inventory management, and design modifications (Barabadi et al., 2011; Barabady and Kumar, 2008; Barabady et al., 2010; Calixto, 2013; Misra, 2008; Naseri et al., 2016; Stapelberg, 2009; Zio, 2009; Zio et al., 2006).

Analysis and assessment of the RAM of a plant extensively rely on detailed historical reliability data on its constituting equipment units, activities, and operations. Such data may be collected from plants' maintenance records or taken from databases. For Arctic regions, the use of reliability data from maintenance reports may be limited because O\&G industry has less experience in these areas compared to those with normal climatic conditions(Barabadi et al., 2015). Various databases have been created such as process equipment reliability database (CCPS, 2016), Offshore Reliability Data handbook (OREDA Participants, 2009), handbook for reliability prediction of mechanical equipment (Center, 2011), electrical equipment (Department of Defense, 1991; IEC, 2004), and safety instrumented systems (Håbrekke et al., 2013).

However, such databases and handbooks do not reflect upon the impact of the harsh environmental and operating conditions on plant RAM performance, and thus their application to Arctic O\&G industry may be associated with a great deal of uncertainty (Artiba et al., 2005; Gao et al., 2010; Homlong et al., 2012; Larsen and Markeset, 2007; Markeset et al., 2015; Naseri and Barabady, 2015b). Such conditions can give rise to the severity of issues involved in plant design and operations. They can also pose additional challenges, which have not been experienced in normal-climate areas such as those related to, for instance, sea ice and iceberg, icing, polar low pressures, etc. Moreover, one also needs to account for the diversity of operating conditions and their year-round variations over the Barents Sea. Weather and meteorological conditions, sea ice extent and thickness, as well as sea ice-covered and openwater periods vary over the Barents Sea due to different flow patterns of warm and cold waters, different wind patterns and speeds, and latitudinal changes in incidence of solar radiation.

In this regard, new models and techniques should be developed or available approaches should be accordingly modified for RAM assessment of O\&G plants operating in Arctic offshore. Of one of the early steps in such efforts is to understand the dominant environmental and operating conditions and their impact on offshore O\&G plants. The aim of this paper is to broadly review and discuss different factors of offshore operating conditions specific to the Barents Sea, and further investigate various effects of such conditions on plant RAM elements. Such an overview and discussion play a key role in building knowledge about O\&G operations in Arctic offshore and their RAM performance and associated risks.

\section{Reliability, availability, maintainability}

Production performance is defined as the "capacity of a system to meet demand for deliveries or performance” (ISO, 2008), which for an O\&G production platform could be, for instance, plant capacity to produce and process certain amounts of oil and gas from subsurface reservoirs. A set of activities may be implemented to achieve and maintain the performance of a plant at its optimum level in terms of overall economy. Such activities, which may include, for instance, developing maintenance strategies, maintenance support and spare parts plans, design 
modification, winterisation, ergonomic design, better material selection, etc., are established by developing and implementing a production assurance programme (ISO, 2008). The effectiveness of such activities and their overall effects on plant production performance should be evaluated quantitatively. Figure 2 illustrates production assurance concept and its key elements, which can be employed for such purposes.

Analysis of plant deliverability and production availability relies on the information acquired by analysing the RAM of plant systems and their constituting elements. Item availability is analysed in accordance with its reliability and maintainability that contribute to item's uptimes and downtimes, respectively. Such information coupled with the failure consequences of system elements can be further used to analyse system availability. In this regard, the focus of this study is limited to RAM concept (see dashed line in Figure 2), which provides key input to the analysis, assessment, and prediction of plant production performance in both the design and operation phases (Calixto, 2013; ISO, 2008; Stapelberg, 2009; Zio, 2009).

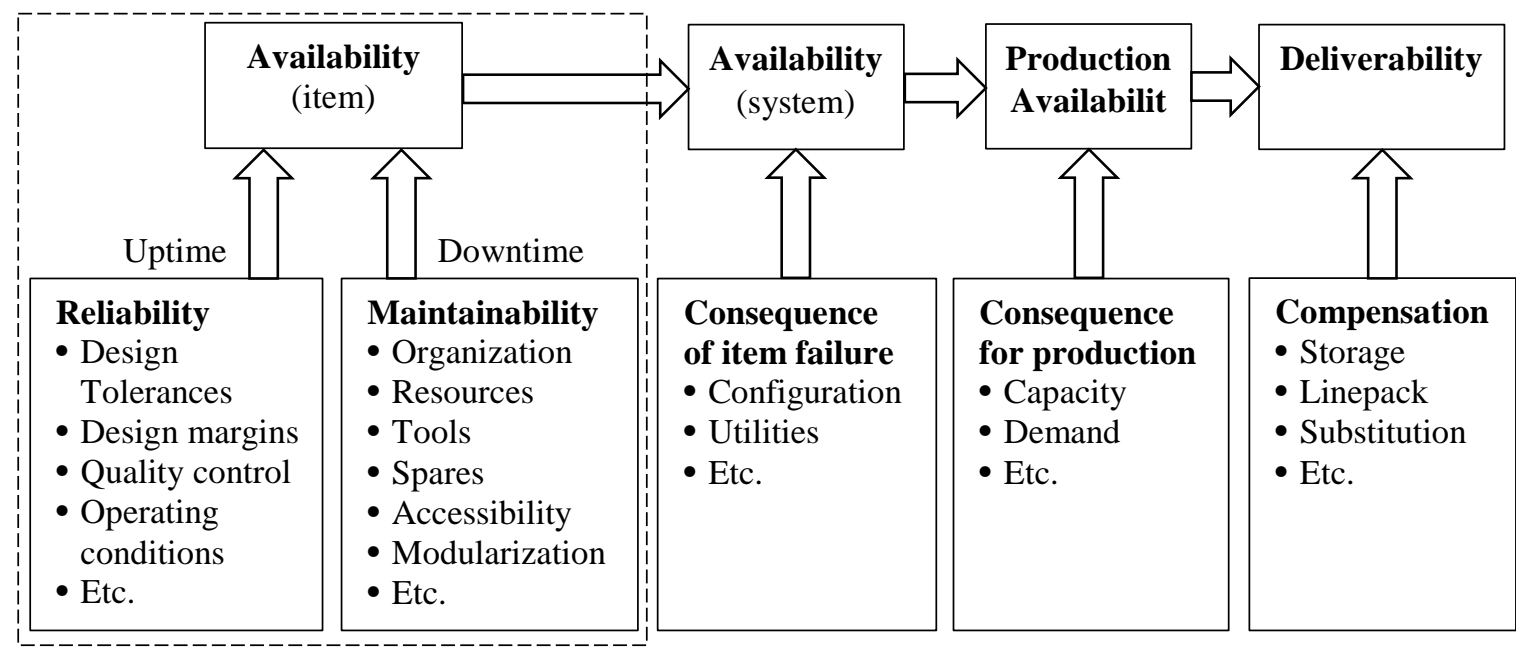

Figure 2. illustration of the relationship between key elements of production assurance concept (ISO, 2008)

\subsection{Reliability}

Reliability is an inherent attribute of a unit or system, which emerge from the interactions of all system elements including, hardware, software, organizational and human (Zio, 2009). For an item (i.e., system constituent) reliability is defined as the ability to perform a required function under given conditions for a given time interval (IEV, 2016; ISO, 2008). Mathematically, item's reliability, $R(t)$, which is the probability that the item survives the time interval $(0, t]$ and is still functioning at time $t$, is given by (Ebeling, 2005; Rausand and Høyland, 2004):

$$
R(t)=\operatorname{Pr}(T>t)=1-\int_{0}^{t} f(u) d u
$$

where $T$ is a random variable denoting time-to-failure of the item and $f(t)$ is the probability density function of item's times-to-failure.

In accordance with reliability definitions, functions of system components and their corresponding failure modes must be clearly specified. Some components may have various functions and operating modes. In this regard, each operation mode or component's function may be associated with its own reliability performance (Barabady et al., 2010; Rausand and 
Høyland, 2004). Furthermore, the conditions under which a component operates should be known. In this regard, "given conditions" can be referred to operating and environmental conditions (e.g., ambient temperature, dust, vibration), operating parameters (e.g., fluid pressure and its $\mathrm{pH}$ level in a pump), operator or maintenance crew skill (e.g., misuse of the system, minimal/imperfect maintenance level), etc. (Barabady et al., 2010; Ebeling, 2005; ISO, 1994; Stapelberg, 2009).

\subsection{Maintainability}

Maintenance is defined as all actions, including technical and administrative, necessary for retaining an item in or restoring a failed item to a state in which it can perform its required functions (Department of Defense, 1981; ISO, 2008). Maintenance activities can be divided into two main categories: corrective maintenance (CM) and preventive maintenance (PM) (Department of Defense, 1981; Rausand and Høyland, 2004; Stapelberg, 2009). CM refers to unplanned maintenance, which includes all actions performed after a fault recognition, in order to restore a failed item to a specified working condition (ISO, 2008). PM, on the other hand, refers to planned maintenance activities. It includes all actions performed in an attempt to retain an item in a specified functioning state by implementing systematic inspection, detection, adjustments, lubrication, parts replacement, calibration, and repair of wearing-out items. PM is carried out to reduce the failure probability of an item or decrease the degradation of its functions, and thus to finally prevent item's failure (Department of Defense, 1981; IEV, 2016; ISO, 2008; Rausand and Høyland, 2004).

Item's downtime can be mainly divided into unplanned and planned downtimes (ISO, 2008), of which the former refers to downtimes associated with CM tasks while the latter is associated with PM tasks and planned activities. Both planned and unplanned downtimes may be considered random variables, although the uncertainties associated with planned downtimes may be less than those associated with unplanned downtimes (Misra, 2008; Rausand and Høyland, 2004).

Unplanned downtimes can be divided into three main sections: active repair time, logistic time, and administrative time (Misra, 2008). Active repair time is mainly the portion of unplanned downtime that is related to actual hand-on works carried out by the maintenance crew to do the repairs. It may be broken down into preparation and access, diagnosis and faultisolation, disassembling, replacement or repair, reassembling, and verification, and alignment times. Logistic time is the portion of downtime, during which a repair is on hold due to the procurement of failed items, shipping delays, loading and offloading delays, i.e., spare part provision delay. Administrative time is the portion of downtime that is mostly due to the delay associated with administrative activities and organising the repair tasks such as issuing spare part request and work orders. Logistic or administrative delay times may also include waiting on personnel, test equipment, support equipment, tools, manuals, etc. (Department of Defense, 1981; Ebeling, 2005; IEV, 2016; ISO, 2008; Misra, 2008). Moreover, a number of preparatory measures may need to be taken before maintenance work is started, some of which are due to safety or operational concerns such as shutting down the process, bypassing the process, depressurisation, cooling equipment down, removal of contents, etc. The time associated with such measures may be also included in active repair time as a part of access time. 
Capability of an organisation to perform maintenance tasks can be evaluated quantitatively using maintainability concept. Maintainability is defined as the ability of an item, under stated conditions of use, to be retained in, or restored to, a state in which it can perform its required functions, when maintenance is performed under stated conditions and using prescribed procedures and resources by personnel having specified skill levels (Department of Defense, 1981; IEV, 2016; Misra, 2008; Stapelberg, 2009).

According to the definition of maintainability, maintenance crew should have adequate skills to fulfil required maintenance tasks. The conditions, under which a maintenance is carried out, can include those affecting the maintenance time, such as location of the failed component, accessibility, organisational factors (e.g., administrative time), inventory level, and weather conditions (Kumar et al., 2012). In this respect, one may consider the maintenance time for maintainability calculation as a combination of active repair time, logistic time, and administrative time as well as their influencing factors (Kumar et al., 2012; Misra, 2008).

Mathematically, maintainability $M(d)$ of an item is measured as the probability that the maintenance is accomplished within time interval $(0, d]$, given by (Ebeling, 2005):

$$
M(d)=\operatorname{Pr}(D \leq d)=\int_{0}^{d} h(u) d u
$$

where $D$ is a random variable denoting downtime and $h(u)$ is the probability density function of item's downtimes. Maintainability analysis requires detailed historical maintenance data, i.e., data on the spent time on each CM or PM task performed previously.

\subsection{Availability}

Availability is defined as the "ability of an item to be in a state to performed a required function under given conditions at a given instant of time, or in average over a given time interval, assuming that the required external resources are provided” (ISO, 2008). In this respect, for an item to be available, it must be in an operable and committable state (i.e., being neither in a failed status nor under repair or maintenance) to start a mission (Department of Defense, 1981). Compared to reliability, availability is a more meaningful parameter for assessing the performance of repairable systems as it includes both system uptime (relating to reliability) and downtime (relating to maintainability) (Ebeling, 2005; Misra, 2008). In this regard, within the concept of dependability, availability is a function of item's reliability, maintainability, and maintenance support performance (IEV, 2016). Therefore, according to different types of system downtime, various types of availability measures have been proposed, including instantaneous, operational, inherent, steady state, and mean availability (IEV, 2016).

Instantaneous availability is one of the most common types of availability measures that states the probability that an item is up and running at a stated instance of time given a set of specified operating condition, independent of the fact that the item has failed or not before that time (Misra, 2008; Rausand and Høyland, 2004). In this respect the availability of an item at time $t$ is given by (Rausand and Høyland, 2004):

$$
A(t)=\operatorname{Pr}(X(t)=1)
$$

where $X(t)$ is the state variable denoting the state of the item at time $t$ such that:

$$
X(t)=\left\{\begin{array}{l}
1 \text { if the item is functioning at time } t \\
0 \text { otherwise }
\end{array}\right.
$$

Mean availability can be also used as a criteria for system performance, which gives the proportion of time during a mission that the system is available for use (Misra, 2008; Rausand 
and Høyland, 2004). Mean availability is simply the average of instantaneous availability over a specified time interval, given by (Rausand and Høyland, 2004):

$$
A_{a v}=\frac{1}{t_{2}-t_{1}} \int_{t_{1}}^{t_{2}} A(t) d t
$$

Availability analysis plays a key role in system life cycle costing and management through optimising spare part inventory plans as well as maintenance policies. Since availability considers both item's reliability and maintainability, any effort on system availability performance can be accomplished through improving system reliability or maintainability.

\section{Key operating conditions in the Barents Sea and their effects on plant RAM performance}

Operating conditions and environmental parameters of Arctic offshore can influence the RAM performance of $O \& G$ platforms and operations in various ways. Identifying such conditions and parameters is the early step of evaluating their effects on plant RAM performance. In this study, the major elements of Barents Sea operating conditions include low ambient temperatures (air, and sea surface); icing events (atmospheric and sea spray) and snow; waves and currents; wind; polar low pressures; sea ice and icebergs; darkness and poor visibility; and remoteness and less-developed infrastructure. The potential interactions of the Barents Sea operating conditions and plant RAM are illustrated in Figure 3.

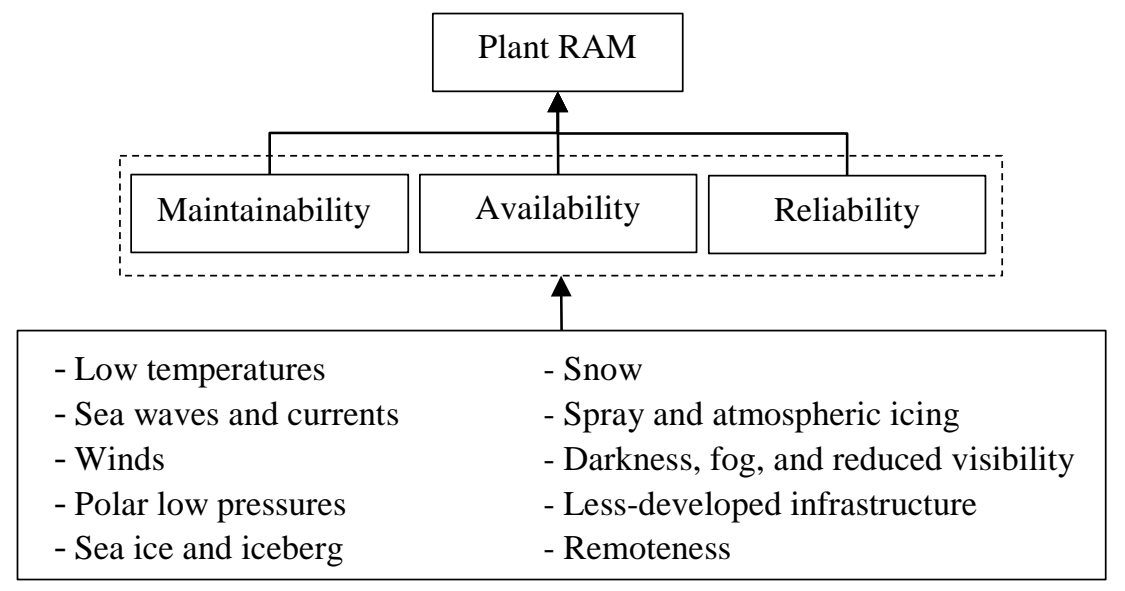

Figure 3. Effects of Barents Sea operating conditions on RAM performance of O\&G platforms and operations

In terms of the reliability, the functionality of equipment units, the effectiveness of the processes and operations (e.g., gas treatment), and the performance of the operation crew can be adversely affected by harsh environmental conditions. The negative impact of environmental conditions on maintainability can be discussed mainly from the viewpoint of extended downtimes due to delays on spare parts provision because of remoteness, lessdeveloped infrastructure, and unavailability of weather window or due to extended repair or maintenance times because of the impact of harsh weather conditions on maintenance crew.

Once the impact of operating conditions on both reliability and maintainability are identified and quantified, the overall effects of operating conditions on plant availability can 
be assessed. That is accomplished considering that plant availability can be described in terms of the combination of its reliability and maintainability.

To analyse the effects of environmental conditions on safety aspects of the plant and operations, one may focus on the performance of safety-instrumented systems and their constituting components, emergency shutdown systems, alarms, detectors, temperature and pressure controllers, fire-extinguishing systems, etc. In this regard, the amount of reduction in the reliability of active barriers (e.g., gas detectors) and passive barriers (e.g., emergency shutdown systems) can be quantified. Moreover, one can update the level of the associated risks by assessing the impact of the Barents Sea operating conditions on different elements of the risk (i.e., new hazards specific to Arctic conditions such as platform-iceberg collision, probability of the occurrence of hazards, and the severity level of hazards' consequences). Finally, structural reliability analysis can be employed to assess the impact of environmental forces such as sea-ice loads, iceberg impact energy, waves and current loads, on structural elements of the plant, for instance, platform legs, haul, and mooring systems.

\subsection{Low ambient temperatures and plant RAM}

\subsubsection{Low ambient temperatures}

Air and sea surface temperatures vary considerably over the Barents Sea during summer and winter periods. The main reasons for such changes include flow of various water masses with different temperatures, diverse wind speeds and directions, latitudinal changes in solar radiation rates, and presence of sea ice in the northern areas and usually open-waters in the west and southwest regions (ISO, 2010; Matishov et al., 2004; Årthun et al., 2012). For instance, while the annual minimum air temperature in the southern parts varies from $-9^{\circ} \mathrm{C}$ to $-6^{\circ} \mathrm{C}$, the northern regions experience an annual minimum temperature of $-39^{\circ} \mathrm{C}$ to $-20^{\circ} \mathrm{C}$ (ISO, 2010). Shallow waters in the eastern and southeastern Barents Sea experience even lower temperatures. For example, minimum temperature at Shtokman and Prirazlomnoye fields is approximately $-28^{\circ} \mathrm{C}$ and $-48^{\circ} \mathrm{C}$, respectively (Nikiforov et al., 2005).

In addition to air temperature, the deep water and sea surface temperatures are also key factors for the design and operation of offshore O\&G plants. That is due to their effects on temperature-dependent processes taking place at the sea bottom (e.g., for instance in subsea wellheads and manifolds) or at the sea level (e.g., flow of wellstream in the production riser).

According to Norwegian Standard N-003, the ambient sea and air temperatures for design purposes in the Norwegian Continental Shelf are those with an annual exceedance probability of $10^{-2}$ (see Figures 4 and 5) (NORSOK, 2007). As shown in Figure 4, sea surface temperature increases towards west and southwest, which is due to the flow of warm Atlantic waters from west. The highest and lowest air temperatures over the Norwegian Continental Shelf, including the Barents Sea, with an annual probability of exceedance of $10^{-2}$ is shown in Figure 5. As can be seen, while minimum air temperature ranges from $-15^{\circ} \mathrm{C}$ to $-10^{\circ} \mathrm{C}$ in the North Sea, the design air temperature varies from $-20^{\circ} \mathrm{C}$ to $-30^{\circ} \mathrm{C}$ in the Norwegian Barents Sea. 


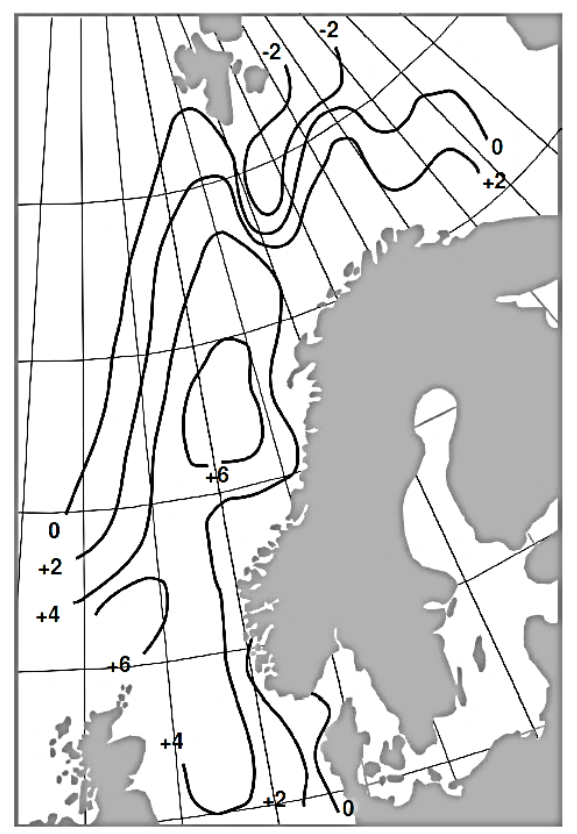

Figure 4. Lowest sea surface temperature $\left({ }^{\circ} \mathrm{C}\right)$ in the Norwegian Continental Shelf with an annual probability of exceedance of $10^{-2}$ (NORSOK, 2007)

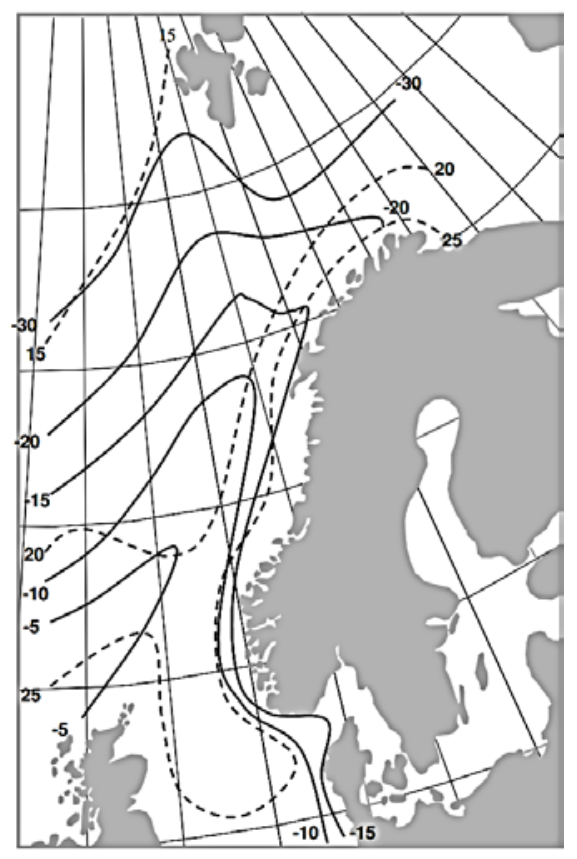

Figure 5. Highest and lowest air temperature $\left({ }^{\circ} \mathrm{C}\right)$ in the Norwegian Continental Shelf with an annual probability of exceedance of $10^{-2}$ (NORSOK, 2007)

\subsubsection{Effects of low ambient temperature on plant RAM performance}

Impact of low temperatures on maintainability can be discussed mainly from the viewpoint of extended downtimes due to the deteriorated performance of the maintenance crew in cold weather. In other words, accomplishing maintenance or repair tasks can take a longer time in cold environment than that in normal-weather conditions due to the negative effects of cold environment on human being's cognitive performance (Markeset et al., 2015; Mäkinen et al., 2006). However, in studies related to cold regions, it is also possible to study the effects of both 
low temperature and wind speed on human performance under the concept of wind chill effect (Bluestein and Quayle, 2003; Osczevski and Bluestein, 2005). Wind chill effect reflects upon not the air temperature, but on the felt temperature by human body, as discussed in Section 3.4.2.

In terms of safety, low temperatures can affect the reliability performance of safety systems or they may cause the failure of safety instruments or equipment units that process gases or hazardous materials. For instance, gas leakage because of pipeline corrosion or plugging is considered a direct safety hazard, which can be due to the buildup of natural gas hydrates in low temperatures (Gasson et al., 2013). In this regard, to assess the impact of low temperature environment on safety aspects of the operations, one could focus on the equipment reliability performance in cold weather. Moreover, one may also consider the reduced performance of the operation or maintenance crew (Markeset et al., 2015), which potentially may result in equipment or process failures leading to hazardous situations.

Low temperatures can have adverse impact on equipment reliability in different ways. Subsea templates, pipelines and flowlines, petroleum de-waxing systems, tankers for storage and transportation of nitrogen and liquefied gases, equipment with any possibility of rapid depressurisation, and all surface systems which are not insulated or heated are some example of the systems that their reliability can be affected by low temperatures (Singh, 2013). Failure probability of equipment units at low temperatures can increase due to the negative impact of temperature on their constituting materials and elements. Low temperatures affect the mechanical properties (e.g., ductile/brittle behaviour) of polymers and metals. They can also change the rheological behaviour of the fluids and thus change the operating parameters of temperature-dependent processes such as separation of wellstream flow, water treatment, gas recompression, etc. (Freitag and McFadden, 1997).

\section{Material properties:}

Materials can be categorised based on their mechanical behaviour and the manner in which they fail. In this regard, brittle/ductile behaviour of polymers and metals is the most crucial mechanical behaviour, which can be affected by low temperatures, considerably (Dutta, 1988; Rudin and Choi, 2013; Singh, 2013).

The change in brittle/ductile behaviour of metals occurs at a molecular level. At low temperatures, the contraction of metals creates stresses that push molecular bonds to a breaking point (Freitag and McFadden, 1997). The extent of the metal embrittlement in low temperatures differs depending on the type of crystal structure of metals. Figure 6 shows the stress-strain behaviour of a typical body-centred-cubic metal (e.g., iron, chromium, columbium, and tungsten) with decreasing temperature. As shown, the ultimate strength point of such metals increases at low temperatures. However, a reduction in temperature makes metals more susceptible to loss of ductility. The reduction in ductility range at low temperatures causes the metal to shatter and fracture when subjected to impact stresses (i.e., brittle failure) (Dutta, 1988; Keane et al., 2013). In this regard, steel and alloys of iron, which have been heat treated to change their crystal structure tend to lose that benefit of treatment at low temperatures and thus are subjected to brittle failures (Freitag and McFadden, 1997). 


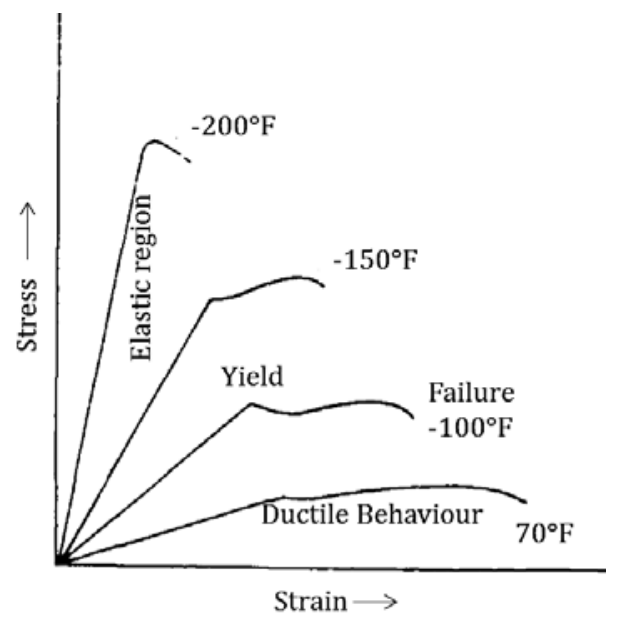

Figure 6. Typical stress-strain curve of a body-centred-cubic class metal (e.g. iron) at different temperatures

(Dutta, 1988)

At low temperatures, polymers show some similarities to metals in terms of brittle behaviour. The thermomechanical behaviour of a typical polymer is depicted in Figure 7. At low temperatures, plastics and polymers show a brittle and less-flexible behaviour. However, the ductile-brittle transition temperature of plastics and polymers differs depending on their type (Freitag and McFadden, 1997; Keane et al., 2013). Due to this brittleness, serviceability of rubber components in for example, tires, inner tubes, cable, hose, bushings and seals, is adversely affected by low temperatures. Inadequate sealing is a common example, which can be caused by the loss of flexibility of rubbers and elastomers at low temperatures (Dutta, 1988; Keane et al., 2013; Rudin and Choi, 2013). The disastrous accident of space shuttle Challenger because of low-temperature-induced failure of O-ring seals is a grim reminder of such problems (Dutta, 1988).

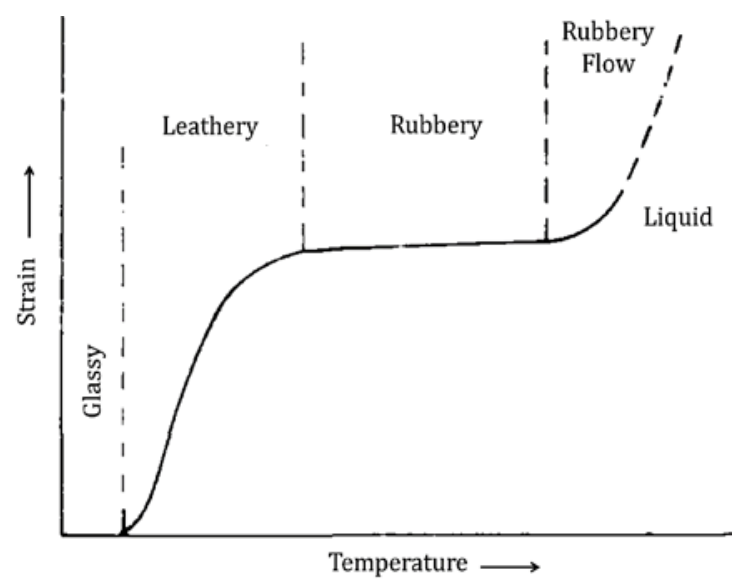

Figure 7. Thermomechanical curve of a typical polymer; shifting from a rubbery region into a brittle (glassy) one (Dutta, 1988)

\section{Fluid properties:}

Low temperatures can change the properties of fluids such as lubricating oils, crude oils, wellstreams, drilling muds and cements, and thus affect their functions. From this viewpoint, low temperatures can contribute to the failure of certain equipment units such as bearings, turbines, pumps, valves, etc. 
Among other physical properties of crude oils and lubricants, viscosity is of utmost importance, as it determines the friction losses. At low temperatures, viscosity of lubricants and crude oils increases sharply when temperature decreases. Such an increase in viscosity requires more energy and thus more operational cost to shear the fluids. It can finally wear out the lubricated contacts (Frêne et al., 1997; Sasanuma and Matsubara, 1995; Satter et al., 2008; Stachowiak and Batchelor, 2006). Moreover, if the ambient temperature decreases below the lubricant crystallisation point, some paraffin wax precipitates. Precipitation of waxes forms interlocking crystals and prevents the flow of oil that leads to the failure of both lubricant and lubricated contacts (Frêne et al., 1997; Stachowiak and Batchelor, 2006). In case of crude oils, wax precipitation can result in corrosion or plugging of connections and pipelines. Additionally, flow of crude oils can be interrupted at low temperatures as oil viscosity increases. An increase of oil viscosity beyond its operating limit can result in a mechanical failure pumping system such as rupture of hoses (Gao and Li, 2012).

Designing and preparing a drilling mud that preservers its properties and fulfils its functions at both low surface temperatures and moderate subsurface temperatures is a challenging task in Arctic offshore drilling operations. Viscosity, yield value, and gel strengths are among the important temperature-dependent rheological parameters of drilling fluids that govern their functions. An increase in the viscosity of drilling muds at low temperatures results in more friction loss in drilling riser, drillstring, casings, and annulus, and thus more energy and cost is required to keep the fluid flow rate and pressure at their designed levels. It can also contribute to the corrosion of pipes and connections (Caenn et al., 2011a; Caenn et al., 2011c). Potential changes in gel strength and yield point of drilling muds can severely affect its cuttingcarrying capacity, which consequently leads to a number of drilling and wellbore problems such as drillpipe stuck. Changes in rheological properties of drilling muds at low temperatures can also occur due to crystallisation and freezing of drilling muds. Salt crystallisation can occur if the ambient temperature is below the crystallisation point of the drilling fluid. Precipitated salts can plug the pipelines, hoses, surface connections, etc. (Caenn et al., 2011b). It can also reduce the density of drilling or completion fluids, which consequently reduces the hydrostatic pressure of the fluid column and potential loss of primary well control barrier by allowing the flow of formation fluid into the wellbore. Such process, also known as kick, if not managed, can escalate to a blowout and threaten the safety of the wellbore, drilling operation, and drilling crew.

Temperature-dependent processes such as water treatment, gas recompression, separation of wellstream, flow of gas in subsea and surface pipelines and facilities, are examples of the operations that their reliability can be deteriorated due to the negative impact of low temperatures on fluid properties. Formation of gas hydrates is another common challenge in gas transport pipelines and in miscible flow of oil and gas in processing facilities. Natural gas hydrates are ice-like solids that form within a specific range of low temperatures and high pressures when small gas molecules become entrapped in the cages of host clathrate lattices made of hydrogen-bonded water molecules (Gasson et al., 2013; Jamaluddin et al., 1991). Formation of gas hydrates can reduce the fluid flow rate and thus increase operational costs. It can create hazardous situations related to the health, safety, and environment, by causing internal corrosions and plugging the pipelines and surface facilities. Pipe corrosion 
itself is responsible for about $50 \%$ of pipe failures such as pipe rupture, gas leakage, explosion, etc. (Obanijesu et al., 2011).

\section{Electrical and electronic devices:}

Functionality of electrical and electronic devices such as cables, wires, switches, pushbuttons, lighting elements, gauges, etc. can be impaired at low temperatures due to the changes in material properties such as ductile-brittle behaviour of metals, plastics, rubbers, and changes in rheological properties of fluids used in such devices.

Electrical insulations on, for instance, wires and cables, may lose their properties or crack at low temperatures and consequently cause hazardous situations (Freitag and McFadden, 1997). Moreover, as temperature decreases, resistance and capacitance of conductors can change and thus lead to potential changes in electrical properties of electrical and electronic components (Keane et al., 2013).

Additionally, in O\&G applications, the safety functions of the electrical and electronic equipment is of vital concern, especially if they are installed in areas with potential leakage of explosive and hazardous gases. This is because the ability of materials to withstand potential gas explosions can be impaired at low temperatures. For instance, it is shown that the pressure produced by igniting explosive gases at low temperatures is greater than that at higher temperatures (Keane et al., 2013). Potential build-up of static charges on plastic surfaces in cold environment due to low humidity increases the possibility of explosions in case of hydrocarbon gas leakage. It may also cause problems for devices such as analogue metres with plastic faces by giving incorrect or erratic readings and thus affect the operation of sensitive controllers, shutdown systems, and alarms (Keane et al., 2013).

\subsection{Snow, icing events, and plant RAM}

Snow is formed in clouds when molecules of water vapour condense on small particles of salt or dust. Shape of snow crystals differs depending on temperature and water saturation. Snow crystals undergo continuous change in shape and size from the moment they are formed until they deposit. The characteristics of deposited snow depends on weather conditions and the form of snow crystals. After deposition, if not melted or evaporated, snow will metamorphose over time into an assemblage of roughly spherical ice grains. This process eventually increases snow density from 0.1 , which is density of a fluffy mass of deposited snow in calm weather to 0.8 , which is ice density. Such an increase in snow density over time is along with a rise in its strength and rigidity, which is known as hardening process. (Freitag and McFadden, 1997). In this regard, one can study the effects of snow on plant RAM performance under the category of either snowdrift or precipitation icing, which the latter is classified as atmospheric icing.

There are generally two types of icing phenomena, classified based on the origin of frozen water: atmospheric icing and sea spray icing. Atmospheric icing refers to the freshwater sources, whereas sea spray icing forms from seawater. The difference between the water sources (i.e. fresh or saline) considerably affects the ice density and its adhesive strength (Ryerson, 2008), and thus the selection and effectiveness of the anti-icing and de-icing methods. 


\subsubsection{Atmospheric icing}

ISO (2001) defines atmospheric icing as "all processes, where drifting or falling water droplets, rain, drizzle or wet snow in the atmosphere freeze or stick to any object exposed to the weather”. In this regard, atmospheric ice can be classified as follow (ISO, 2001; Parent and Ilinca, 2011; Ryerson, 2008).

- In-cloud icing: In-cloud icing happens when supercooled water droplets hit a surface below $0^{\circ} \mathrm{C}$ and freeze upon impact in the presence of a minimal wind speed of $2 \mathrm{~m} / \mathrm{s}$. The temperature of the droplets can be as low as $-30^{\circ} \mathrm{C}$, but they do not freeze in the air due to their small size. Accretion rate and properties of in-cloud ice vary depending on the number of droplets in the air, droplet size, liquid water content in the air, air and droplet temperature, wind speed, icing duration, and the collection efficiency of the structure. Rime is the most common type of in-cloud icing, which can be divided into soft and hard depending on wind speed and air temperature. Figure 8 illustrates the formation of different types of atmospheric ice under various regimes of wind speed and air temperature.

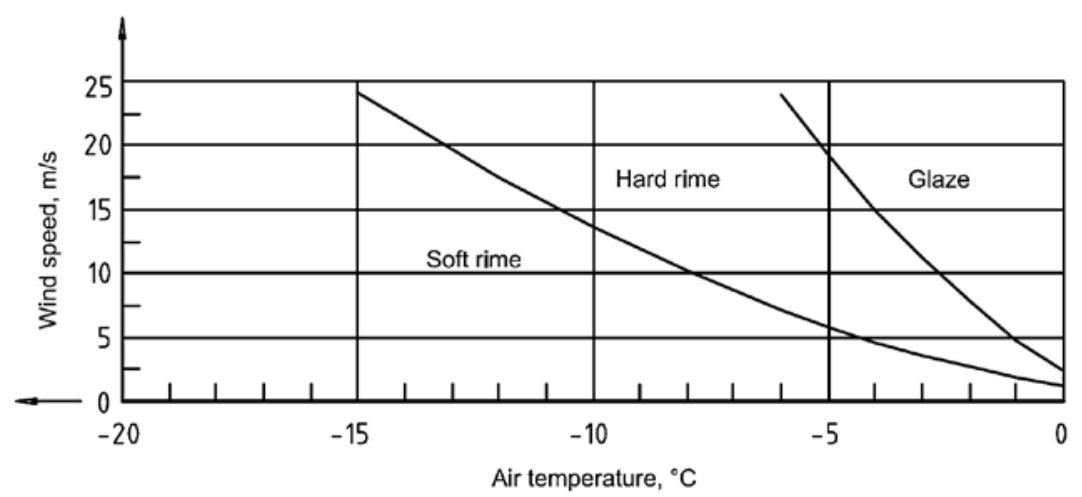

Figure 8. Indication of the parameters controlling the major types of atmospheric ice formation (ISO, 2001)

- Precipitation icing: Precipitation icing is generally in the form of freezing drizzle, rain, glaze, sleet, and wet snow accumulation, with an accretion rate higher than that of incloud icing. Freezing rain or drizzle occurs when rain falls on a surface whose temperature is below $0^{\circ} \mathrm{C}$. When rain does not freeze upon impact, it runs back on the surface and freezes later. The resulting ice is called glaze, which has the highest density and adhesive strength among the other types of atmospheric ice. Sleet forms when raindrops freeze before reaching the surface. If the sleets accumulate and refreeze together, they form a considerably adhesive ice. Wet snow happens when the air temperature is slightly above the freezing point. Its density and adhesive strength greatly depend on the fraction of melted water and wind speed. Removal of wet snow becomes difficult if it freezes on the surface with further decrease in temperature.

- Frost icing: Frost appears when water vapour solidifies directly on a cool surface, often during slow winds. Frost ice has low density and strength, and normally does not result in significant hazard. 


\subsubsection{Sea spray icing}

Sea spray icing is considered as the most severe icing event due to its potentially high accumulation rate (Ryerson, 2008). Modelling of spray ice generation, and quantifying its accumulation rate vary depending on where it forms on platforms and vessels (Jones and Andreas, 2009). The majority of spray ice on vessels is generated by heaving and pitching as the vessel interacts with the waves it is moving through (Funk, 2012; Jones and Andreas, 2009; Ryerson, 2008). Figure 9 illustrates the splash of seawater due to vessel-wave interaction and resulting spray icing on deck.

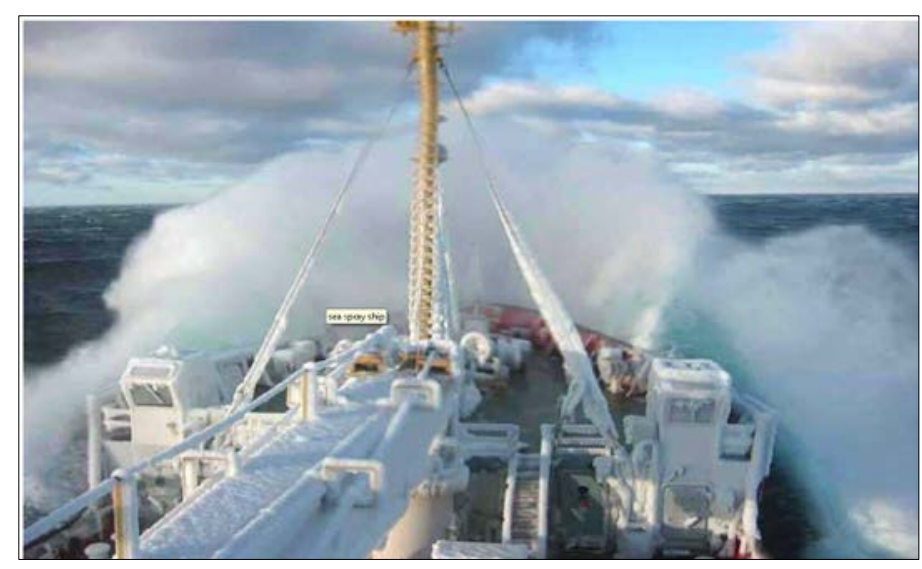

Figure 9. Vessel-wave interaction and resulting sea spray icing on the deck (Toomey et al., 2010)

Platforms, on the other hand, are stationary, which are either sitting directly on the sea bottom (i.e., bottom-supported platforms) or anchored (i.e., floating platforms). Therefore, spray ice on platforms forms when wind-blown water droplets, generated from whitecaps on the ocean surface, strike the structure (Ryerson, 2008). Figure 10 shows heavy spray icing on Ocean Bounty platform in Cook Inlet Alaska. However, depending on the elevation of different platform's parts, the amount and type of icing may vary. Figure 11 shows possible places of a floating platform, where atmospheric and spray ice may form. Although atmospheric icing can occur on lower parts of the structures, it will be later washed away by waves or covered by spray ice.

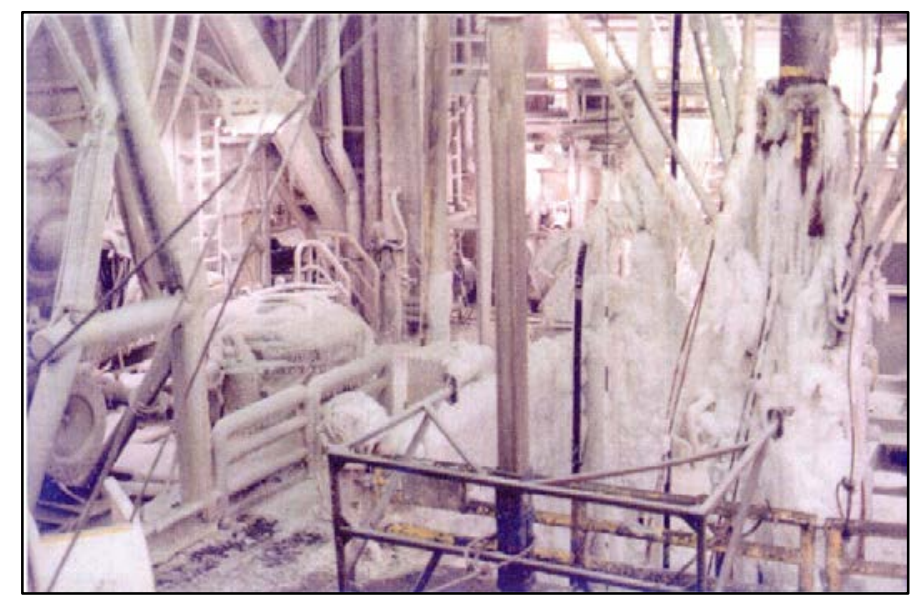

Figure 10. Sea spray icing on Ocean Bounty platform in the winter of 1979-1980 in Cook Inlet, Alaska (Jones and Andreas, 2009) 


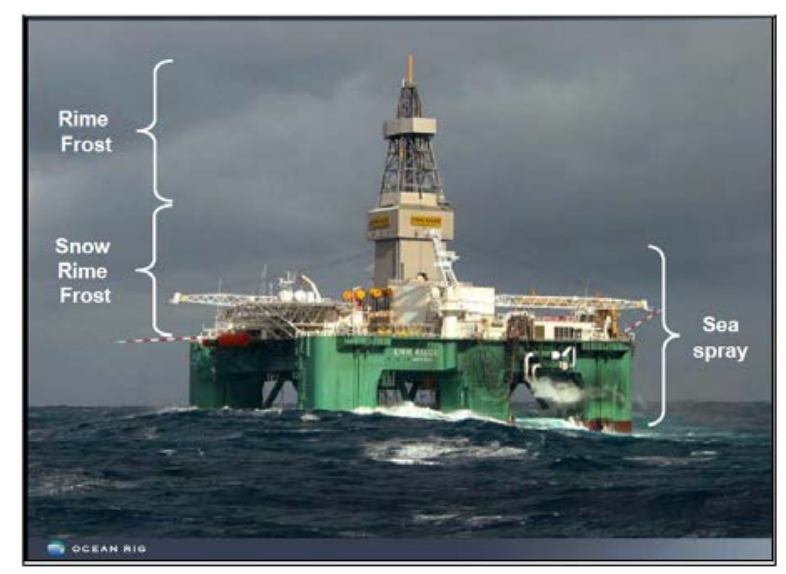

Figure 11. Potential ice accretion areas by ice type on a platform (Ryerson, 2008)

\section{Parameters affecting sea-spray icing rate:}

The amount of accreted spray ice, its thickness, and its possible location on a vessel or platform depend on a number of factors including metocean conditions, shape and location of the equipment on-board, characteristics and type of the surface, design characteristics of the platform or vessel, etc. Understanding the effects of these parameters on icing rate, its thickness, and its mechanical characteristics on different surfaces provide a robust basis for modelling icing process, as well as designing and implementing anti-icing and de-icing strategies. The main elements governing the properties and accretion rate of spray ice properties are described below:

- Wind: Higher wind speeds increase the volume of spray flux and cooling rate of water droplets, which consequently result in sever icing conditions and thicker spray ice (Jones and Andreas, 2009; Ryerson, 2008). Additionally, icing rate is affected by wind direction with respect to the shape and location of on-board equipment units. For instance, icing rate on the windward side of the structures is considerably higher than on the other sides.

- Air temperature: A freezing process requires an air temperature below seawater freezing point, which itself depends on the water salinity (Kulyakhtin et al., 2012). The freezing point of seawater with a typical salinity of $35 \mathrm{~g} / \mathrm{l}$ is approximately $-1.8^{\circ} \mathrm{C}$ at an atmospheric pressure (Guest, 2005; Jones and Andreas, 2009). Lower air temperatures increase the icing rate by accelerating the heat loss process in water droplets. However, for a given seawater salinity, sea surface temperature, and wind speed, there is a minimum air temperature, below which icing rate drops considerably as water droplets freeze in the air before striking the structures (Lundqvist and Udin, 1977). Air temperature also affects the mechanical properties of accreted spray ice. At low temperatures, the process of brine expulsion from ice is accelerated, which consequently leads to forming a harder ice with higher adhesive strength (Ryerson, 2008).

- Sea surface temperature: Low sea surface temperatures increase the rate of spray icing due to less amount of heat loss required for freezing process (Funk, 2012; Lundqvist and Udin, 1977; Ryerson, 2008). Although some spray icing events have been reported 
for a sea surface temperature of $3-6^{\circ} \mathrm{C}$, the most probable sea water temperature for different icing severities is below $3^{\circ} \mathrm{C}$ (Lundqvist and Udin, 1977).

- Salinity of sea water: An increase in seawater salinity affects spray icing rate by lowering water freezing point (Kulyakhtin et al., 2012). The salinity of the Barents Sea and thus its freezing point vary because of different flow of water masses (i.e., warm saline Atlantic waters and cold less-saline Arctic waters) (Loeng, 1991; Løset et al., 1999).

- Volume of spray flux: Apart from meteorological conditions, the severity of spray icing depends on the amount of available water droplets (Lundqvist and Udin, 1977). For instance, wind-generated spray has a lower volume of water droplets compared to that generated by vessel-wave interaction. Moreover, the amount of spray icing on the upper locations of the structure above ocean surface is less than that of accreted on lower heights as larger droplets fall out of spray cloud due to gravity. It has been also reported that there is no spray icing near waterline, due to the washing and heating effect of ocean water (Jones and Andreas, 2009; Ryerson, 2008).

- Sea wave: Especially in spray icing on vessels, sea wave characteristics are important parameters for determining the volume of spray flux (Funk, 2012; Jones and Andreas, 2009). Sea wave can also contribute to spray icing on platforms. In considerably high waves, water droplets are generated from whitecaps in higher elevations. Therefore, their chance of striking the upper parts of the platform increases.

There are also other factors such as ship length, ship speed, hull shape, freeboard, and ship heading, which influence the amount of spray on the vessel deck (Funk, 2012; Guest, 2005; Jones and Andreas, 2009). For instance, smaller vessels with lower freeboards are subjected to more ice accumulations compared to large supply vessels (Guest, 2005).

\subsubsection{Effects of snow and icing events on plant RAM performance}

Icing and snow accumulation can have adverse effects on plant RAM performance in various ways. Spray icing on platforms and vessels can be as heavy as 200 to 1600 tons (Liljestrom, 1985). If not adequately designed, spray icing can severely threaten the stability of vessels and platforms. For instance, in the winter of 1979-1980 in Lower Cook Inlet, Alaska, the semisubmersible drilling platform, Ocean Bounty, experienced six icing storms in a 121-day period. Because of the huge amount of accreted spray ice, the drilling mud had to be offloaded to avoid losing platform stability (Jones and Andreas, 2009). Spray icing, however, is a more concerning safety factor for offshore supply vessels especially the smaller ones with lower freeboards (Duval, 1975; Guest, 2005).

Huge spray ice accumulation on the windward side of the platforms and vessels can cause an imbalance in the structure, resulting in healing problems and thus affecting the vessel or platform's motion characteristics (Ryerson, 2008). In this regard, huge spray icing may threaten the safety of crew on-board and structural reliability of the platform and vessels. In addition, it may interrupt routine operations on-board due to safety concerns (e.g., loss of platform's motion characteristics). It also may result in unplanned delays in delivering platform needs such as spare parts and thus contribute to an extended operation downtime.

Asymmetric spray icing can happen due to the changes in prevailing icing direction and growth of different ice classes. Asymmetric or unbalanced accreted ice on, for instance, guyed 
masts (ISO, 2001) can unbalance the forces and thus threatens their stability or increases the fatigue failure possibility. Loads imposed by ice on equipment and shelter ceilings may cause damage and malfunction (Ryerson, 2008; Ryerson, 2011). Ice sticks easily to surface imperfections such as joints and welds. It also accretes faster on small diameter tubes, chains, ropes, pipes, connections, etc., compared to the larger ones (Baller and Friedberg, 1984). Additional loads of ice on such components can cause failure or interrupt involved operations leading to a decreased availability of affected components.

Figure 12 shows some equipment units covered by spray ice. Less accessibility to such equipment interrupts operations and maintenance tasks (Markeset et al., 2015). Similar issues can arise due to the accumulation of wind-blown snow in low-velocity areas. Cleaning of snow and removal of ice in order to access failed components increase the active repair time, as well as operational delays and costs. Additionally, slippery surfaces because of ice or hardened snow can contribute to an extended downtime by negatively affecting the performance of maintenance crew.

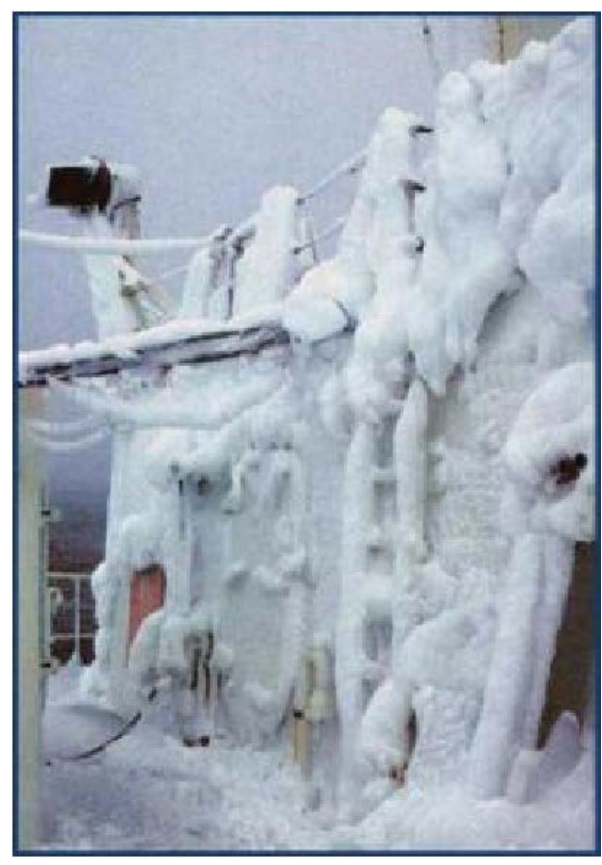

Figure 12. Less accessibility to ice-covered equipment units interrupts the operation and increases the maintenance time if they fail (Guest, 2005)

Spray ice and accumulated snow can cause considerable safety hazards for personnel and equipment aboard. Falling ice and compacted snow during thawing, as well as slippery stairways and deck can cause personnel injuries and potentially increase human error rates (ISO, 2001; Ryerson, 2008). Heavy accretion of ice and accumulation of snow on doors, stairways, pathways, helicopter pad, and life rafts can considerably impair the escape and evacuation efforts in case of emergencies (Crowley, 1988; Ryerson, 2011). Accreted ice or accumulated snow on fire-fighting equipment, ventilations, and manual emergency shutdown systems imposes serious safety and health hazards by reducing the reliability of passive safety barriers.

Atmospheric icing mainly affects the derricks, masts, helicopter pad fittings, radars, and other exposed structures (Baller, 1983). Additionally, atmospheric icing and salt-water spray 
icing on antennas can cause a blind arc distorting radars and signals, and thus decreasing the safety of navigation (Crowley, 1988; Funk, 2012; Guest, 2005; Keane et al., 2013). Wind action on iced structures such as antennas is different from the un-iced ones, which is due to the larger drag coefficient for ice-covered structures.

\subsection{Waves, currents, and plant RAM}

\subsubsection{Waves and currents}

Water masses in the Barents Sea consist of mainly warm Atlantic waters, Norwegian coastal waters, and cold Arctic waters (ISO, 2010; Loeng, 1991; Løset et al., 1999; Årthun et al., 2012), of which the coastal waters enter the Barents Sea from southeast parallel to the coast of Norway and move eastward towards Pechora Sea, south of Novaya Zemlya. A shown in Figure 13, the Atlantic and Norwegian coastal currents enter the Barents Sea from the south and southwest between the northern coast of Norway and Bjørnøya. Surface speeds of $0.75-0.8 \mathrm{~m} / \mathrm{s}$ has been recorded in the western Barents Sea between warm Atlantic waters and Norwegian coastal waters. They are further divided into two main branches, of which one flows towards the western coast of Spitsbergen and the other one flows eastwards along the northern coast of Norway (Løset et al., 1999). Warm Atlantic waters that flow towards east become colder and fresher, and finally drift towards northwest where they eventually exit the Barents Sea between Novaya Zemlya and Franz Josef Land. The northwestern Barents Sea is dominated by Arctic water masses with negative temperatures and decreased salinity, which enter the Barents Sea between Svalbard and Franz Josef Land. They finally flow southwestward where the polar front is formed (ISO, 2010; Matishov et al., 2004; Årthun et al., 2012).

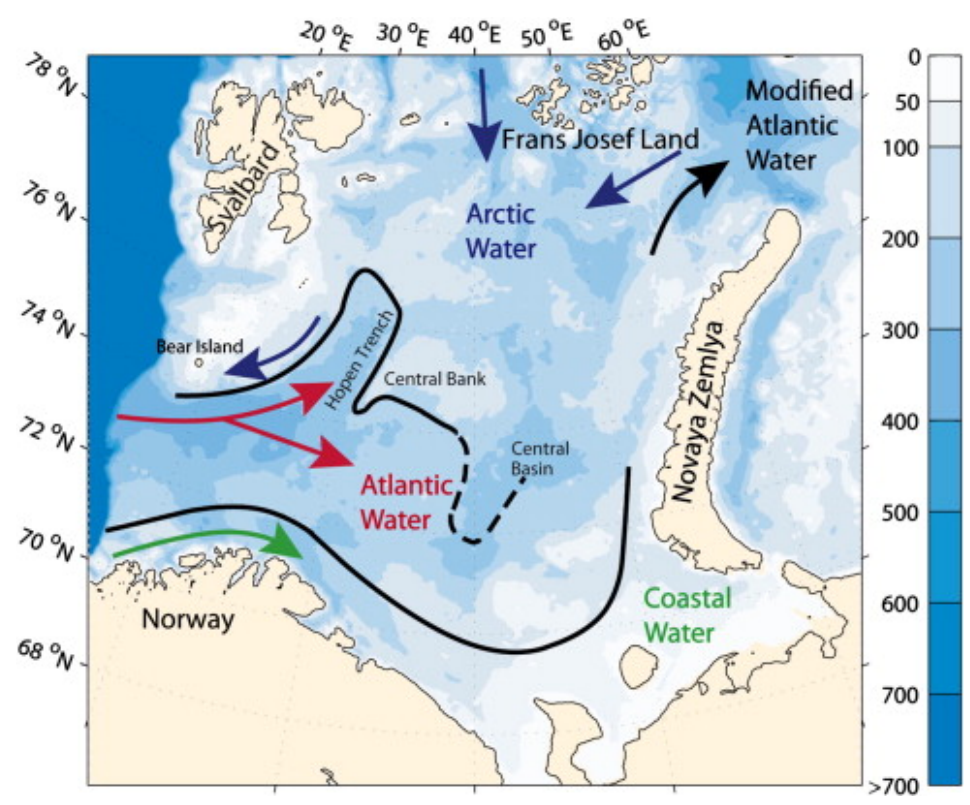

Figure 13. Schematic of main water masses in the Barents Sea - black lines represent frontal areas (Årthun et al., 2012)

Design of offshore facilities requires the specification and extreme return-period of wave parameters such as height, period, and propagation direction (ISO, 2005). Figure 14a shows significant wave height and maximum peak period over the Norwegian Continental Shelf with 
an annual probability of exceedance of $10^{-2}$. As shown, although there is a little variation in the mean significant wave height and wave period over the western Barents Sea, their magnitudes decrease eastward (NORSOK, 2007). Figure 14b shows the 100-year return-period speed of tidal surface currents in the central and western Barents Sea (NORSOK, 2007).

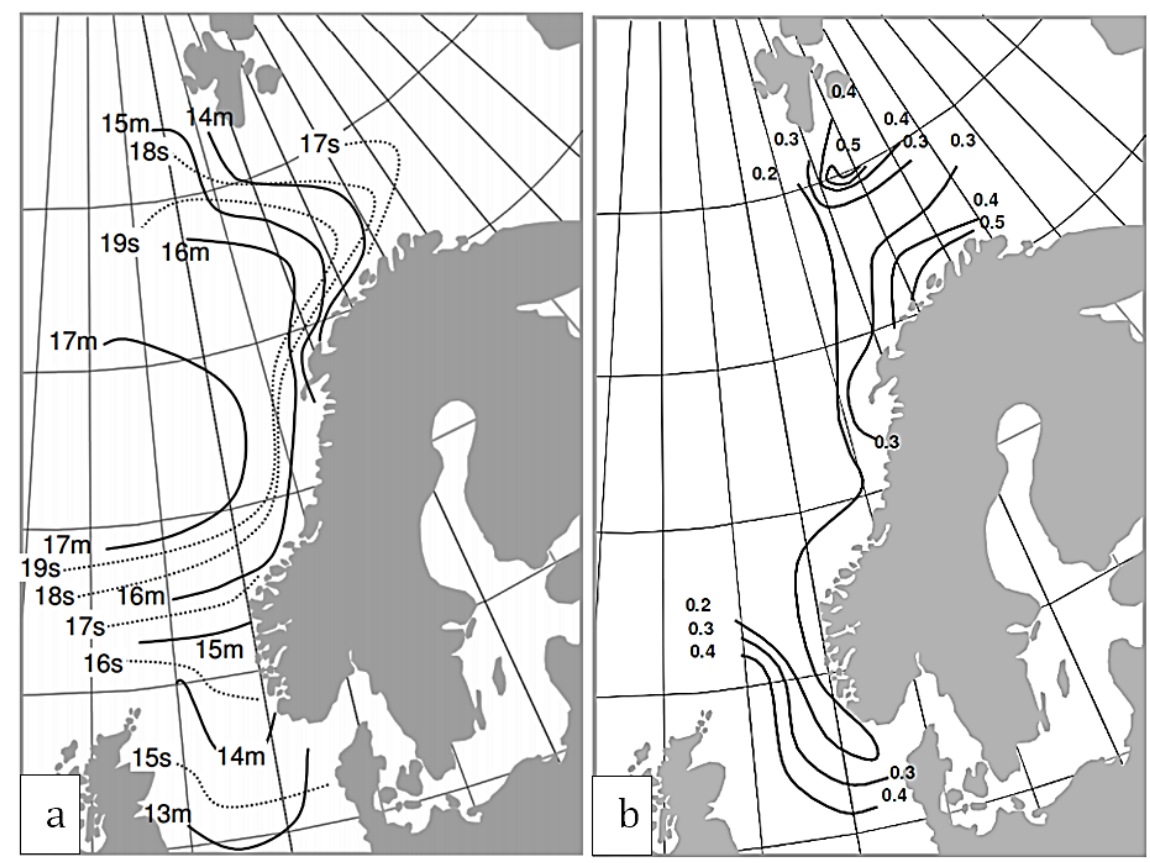

Figure 14. a) Significant wave height (solid line), in metre, and related maximum peak period (dotted line), in second, with annual probability of exceedance of $10^{-2}$ in the Norwegian Continental Shelf; b) Tidal surface current speed in $\mathrm{m} / \mathrm{s}$ in the Norwegian Continental Shelf with annual probability of exceedance of $10^{-2}$

(NORSOK, 2007)

\subsubsection{Effects of waves and currents on plant RAM performance}

The design of O\&G offshore facilities involves analysing the impact of a variety of forces exerted by waves and currents on platforms. Such forces include, for instance, global and local forces on overall structure and structural components as well as lateral and vertical forces on mooring system, drilling and production risers, flexible joints, and flow lines (El-Reedy, 2012; Hodgins and Hodgins, 1991; ISO, 2005; Journée and Massie, 2001). Such forces can threaten the overall stability of vessels and platforms and cause fatigue failure of structural equipment units on-board, as well as elements and joints at both the sea surface and sea bottom (e.g., subsea template and wellhead connecting joints).

The vertical motion of the platform due to the forces exerted by sea waves and currents is controlled by employing heave compensators. Failure of heave compensators or inadequate design of platform vertical motions can lead to the loss of wellbore due to the failure of the elements connecting the platform to the sea bottom facilities, such as production or drilling rises.

Horizontal motion of the structure is another factor of importance for the operation of vessels and offshore platforms. To make sure that the unit is kept in place, the horizontal forces exerted by waves and currents are compensated for by using station-keeping systems such as mooring or dynamic positioning systems (Journée and Massie, 2001). However ensuring a highly reliable station-keeping system requires a thorough understanding of the effects of 
environmental conditions on different elements of mooring or dynamic positioning systems. Those includes, for instance, loads exerted by currents and waves as well as the impact of possible corrosive environment that can accelerate fatigue failure, especially in joints and connection areas (Azar and Samuel, 2007). Loss of the station-keeping system of Deepwater Horizon drilling platform in the Gulf of Mexico in 2010 is a case in point where the forces exerted by waves and currents contributed to a catastrophe. While the dynamic positioning system of the platform failed due to loss of electricity, the flexible joint of the subsea blowout preventer failed due to the forces exerted by waves and currents. Such a situation was further escalated into a complete loss of the wellbore and a devastating environmental impact (Deepwater Horizon Study Group, 2011).

Additional considerations must be paid to the design of adequate air gap in order to reduce the possibility of sea spray icing on the deck and topside facilities. In this regard, the distribution of extreme and abnormal crest elevation are required for setting minimum deck heights on bottom-founded structures and avoiding the intrusion of seawater onto the platform (ISO, 2005).

Sea conditions can also contribute to the safety of the operations and crew by heaving and swaying the platform and thus creating hazardous situations for crew and equipment onboard. High sea conditions can create uncomfortable working environment for maintenance crew and consequently increase active repair times. Delivery time of spare parts by offshore supply vessels depends, among other factors, on wave height, wind speed, and sea ice conditions. Rough sea conditions together with strong winds can extend the cruising time, and thus add additional logistic delays and cost to the operations. Moreover, crane operations and offloading of delivered spare parts on platforms can be interrupted or delayed by high waves. Such logistic delays extend equipment downtimes and thus decrease plant availability.

\subsection{Winds and plant RAM}

\subsubsection{Wind}

Strong winds and cyclones, forming in the North Atlantic Ocean and moving southward and into the central part of the Barents Sea, are among the important parameters determining wind speeds and their directions over the Barents Sea during summer and winter (ISO, 2010). Average wind speeds in the northern and central Barents Sea range from 8.0-9.0 m/s, and 6.0$10.0 \mathrm{~m} / \mathrm{s}$, respectively (Løset et al., 1999). Generally, the highest wind speed appears around Bjørnøya, where the extreme values exceed $36 \mathrm{~m} / \mathrm{s}$ (Gudmestad, 1999; Løset et al., 1999). The 50 -year return period gust is $40 \mathrm{~m} / \mathrm{s}$ in the central Barents Sea, and $41 \mathrm{~m} / \mathrm{s}$ in the southeastern parts near the Pechora Sea. Additionally, polar low pressures create high-speed cyclonical shape winds and storms in the western and southwestern Barents Sea. For example a polar low pressure on 6th February 2012, created strong winds with maximum speed of $20 \mathrm{~m} / \mathrm{s}$ (Norwegian Meteorological Institutte, 2013), while the average wind speed in that area during winter is around $9.6 \mathrm{~m} / \mathrm{s}$ (Gudmestad, 1999).

\subsubsection{Effects of winds on plant RAM performance}

In terms of reliability and safety, winds can give rise to the design challenges as they exert forces on overall structure and its elements. They can cause instability problems or fatigue 
failures especially for elevated elements such as flare-booms and derricks. Moreover, wind forces become critical design factors especially for components, which may experience an asymmetric spray or atmospheric icing situation (see Section 3.2.3) (Hodgins and Hodgins, 1991; ISO, 2005). Forces exerted by high-speed winds may also affect the reliability performance of crane and helicopter operations and thus lead to safety hazards for personnel (NORSOK, 2007). High-speed winds and their resulted waves may deteriorate the performance of oil spill removal methods such as mechanical oil recovery by booms and skimmers and increase environmental impacts (Fingas, 2011; Naseri and Barabady, 2015a).

Winds can pose delays or interrupts offloading of spare parts and increase logistic delays and costs. They can increase active repair times by adversely affecting the performance of maintenance crew. Such adverse effects are usually described in combination of low temperatures, which reduce the felt temperatures by human body (Markeset et al., 2015). This process is known as wind chill effect (Bluestein and Quayle, 2003; Osczevski and Bluestein, 2005). In this regard, an equivalent ambient temperature is required to account for both air temperatures and wind speeds. To this aim, wind chill temperature is defined as "the air temperature with no appreciable wind (i.e., still air) that would affect the same heat loss rate from exposed skin, as that due to the actual dry bulb temperature with wind" (Bluestein and Quayle, 2003). One of the most widely used wind chill models is developed by Osczevski and Blusestein in 2001, presented in Table 1 (Bluestein and Quayle, 2003; Osczevski and Bluestein, 2005). According to this model, the equivalent wind chill temperature drops considerably at low temperatures and high-speed winds.

Table 1. Wind chill equivalent temperature $\left({ }^{\circ} \mathrm{C}\right)$ chart, with air temperature in ${ }^{\circ} \mathrm{C}$ and wind speed in $\mathrm{km} / \mathrm{h}$.

Shaded area indicates when frostbite can occur in less than 30 minutes (Osczevski and Bluestein, 2005)

\begin{tabular}{|c|c|c|c|c|c|c|c|c|c|c|c|c|c|}
\hline \multicolumn{14}{|c|}{ Air Temperature $\left({ }^{\circ} \mathrm{C}\right)$} \\
\hline Calm & 10 & 5 & 0 & -5 & -10 & -15 & -20 & -25 & -30 & -35 & -40 & -45 & -50 \\
\hline 10 & 9 & 3 & -3 & 9 & -15 & -21 & -27 & -33 & -39 & -45 & -51 & -57 & -63 \\
\hline 15 & 8 & 2 & -4 & -11 & -17 & -23 & -29 & -35 & -41 & -48 & -54 & -60 & -66 \\
\hline 20 & 7 & 1 & -5 & -12 & -18 & -24 & -31 & -37 & -43 & -49 & -56 & -62 & -68 \\
\hline 25 & 7 & 1 & -6 & -12 & -19 & -25 & -32 & -38 & -45 & -51 & -57 & -64 & -70 \\
\hline 30 & 7 & 0 & -7 & -13 & -19 & -26 & -33 & -39 & -46 & -52 & -59 & -65 & -72 \\
\hline 35 & 6 & 0 & -7 & -14 & -20 & -27 & -33 & -40 & -47 & -53 & -60 & -66 & -73 \\
\hline 40 & 6 & -1 & -7 & -14 & -21 & -27 & -34 & -41 & -48 & -54 & -61 & -68 & -74 \\
\hline 45 & 6 & -1 & -8 & -15 & -21 & -28 & -35 & -42 & -48 & -55 & -62 & -69 & -75 \\
\hline 50 & 6 & -1 & -8 & -15 & -22 & -29 & -35 & -42 & -49 & -56 & -63 & -70 & -76 \\
\hline 55 & 5 & -2 & -9 & -15 & -22 & -29 & -36 & -43 & -50 & -57 & -63 & -70 & -77 \\
\hline 60 & 5 & -2 & -9 & -16 & -23 & -30 & -37 & -43 & -50 & -57 & -64 & -71 & -78 \\
\hline 70 & 5 & -2 & -9 & -16 & -23 & -30 & -37 & -44 & -51 & -59 & -66 & -73 & -80 \\
\hline 80 & 4 & -3 & -10 & -17 & -24 & -31 & -38 & -45 & -52 & -60 & -67 & -74 & -81 \\
\hline
\end{tabular}

In general, wind speed over the Barents Sea is less than that over the North Sea and Norwegian Seas. An example of this trend is illustrated in Figure 15, where the probability density function of wind speeds over four different areas in the North Sea (Ekofisk Platform), the Norwegian Sea (Draugan), and the Barents Sea (Hopen and Bjørnøya) are depicted. However, such comparatively low wind speeds do not necessarily indicate a lower level of risks associated with winds in the Barents Sea operations. This is of special importance, if one considers the impact of wind speeds on components such as antenna covered by ice. Similarly, the impact of wind speeds on crew performance in the Barents Sea could be potentially severer than that in normal-climate regions due to wind chill effect. To compare the combined effects 
of air temperatures and wind speeds, the probability density function of wind chill temperatures in above-mentioned four regions in the Norwegian Continental Shelf is depicted in Figure 16. As can be seen, Hopen and Bjørnøya are associated with comparatively higher wind chill temperatures than those in the North and Norwegian Seas.

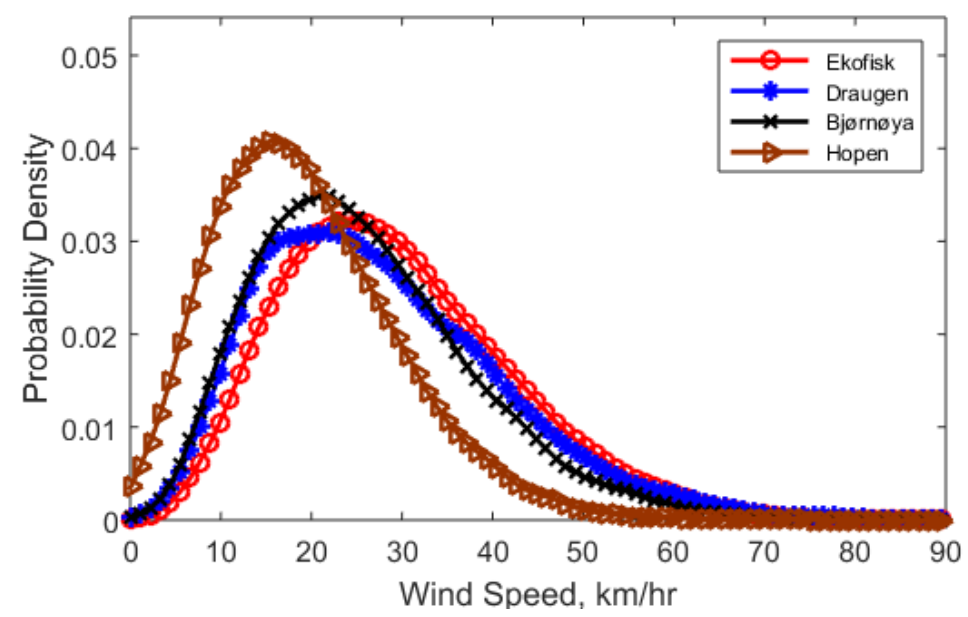

Figure 15. Probability density function of wind speeds in $\mathrm{km} / \mathrm{hr}$ over four locations in the Norwegian Continental Shelf (data from Norwegian Meteorological Institute database, www.eklima.no)

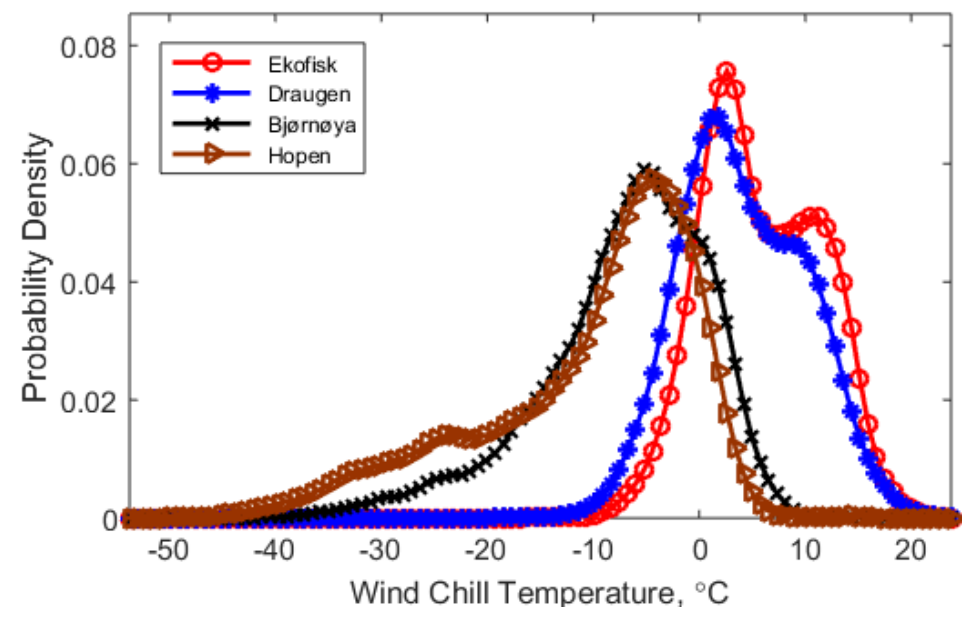

Figure 16. Probability density function of wind chill temperatures in ${ }^{\circ} \mathrm{C}$ over four locations in the Norwegian Continental Shelf (wind speed and air temperature data are taken from Norwegian Meteorological Institute database, www.eklima.no; wind chill temperature is calculated using the method developed by Osczevski and Bluestein (2005))

\subsection{Polar low pressures and plant RAM}

\subsubsection{Polar low pressures}

Polar low pressures (see Figure 17) are common meteorological phenomena in the Barents Sea, which mainly form from September to early summer when a system of cold polar air moves over relatively ice-free warmer waters (Hamilton, 2004). Polar low pressures, which generally have a diameter of 200 to $1000 \mathrm{~km}$, are associated with sudden weather changes in terms of increased wind speed and wave height, decreased air temperature and considerable snow showers (Rasmussen and Turner, 2003). Some of the characteristics of polar low pressures are 
as follows (Bulakh et al., 2011; Carstens, 1983; Carstens, 1985; Hamilton, 2004; Rasmussen and Turner, 2003):

- Life span of 6 to 48 hours from initiation to decay

- Difficult to predict

- Rapid development (calm weathers turn into severe storms in about 10 minutes)

- Associated with gale or storm force winds

- Associated with heavy snow showers, icing events, and changes in wind direction

- Associated with decreased visibility due to snowstorms (visibility of less than $50 \mathrm{~m}$ )

- Associated with decreased air temperature to about $-30^{\circ} \mathrm{C}$

- Associated with high waves up to $15 \mathrm{~m}$

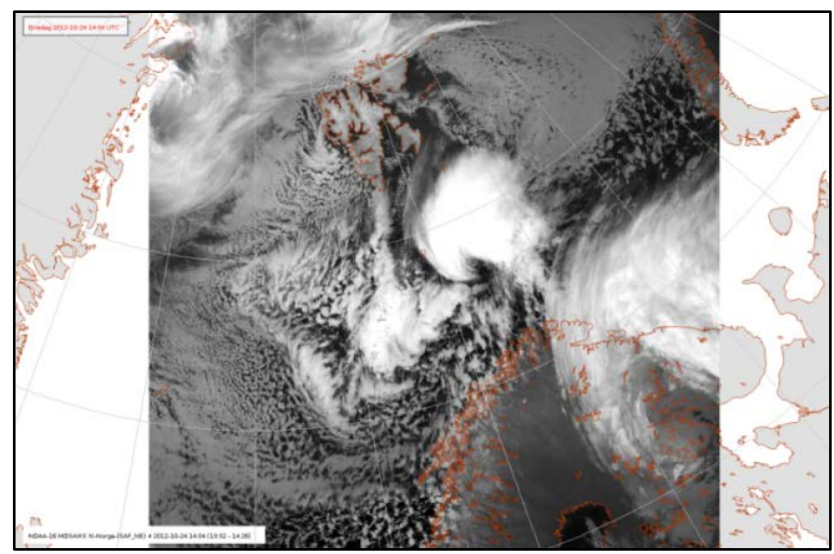

Figure 17. A polar low pressure in the western the Barents Sea on 24th October 2012, associated with the maximum snow depth of $82 \mathrm{~cm}$, lasted for about 24 hours (Source: Norwegian Meteorological Institute)

Figure 18 depicts a historical occurrence of polar low pressures over the Barents and Norwegian Seas. As shown, polar low pressures form more frequently in the southwestern Barents Sea, where relatively warm Atlantic waters meet colder Arctic ones. Current main Norwegian hydrocarbon fields are located in this area.

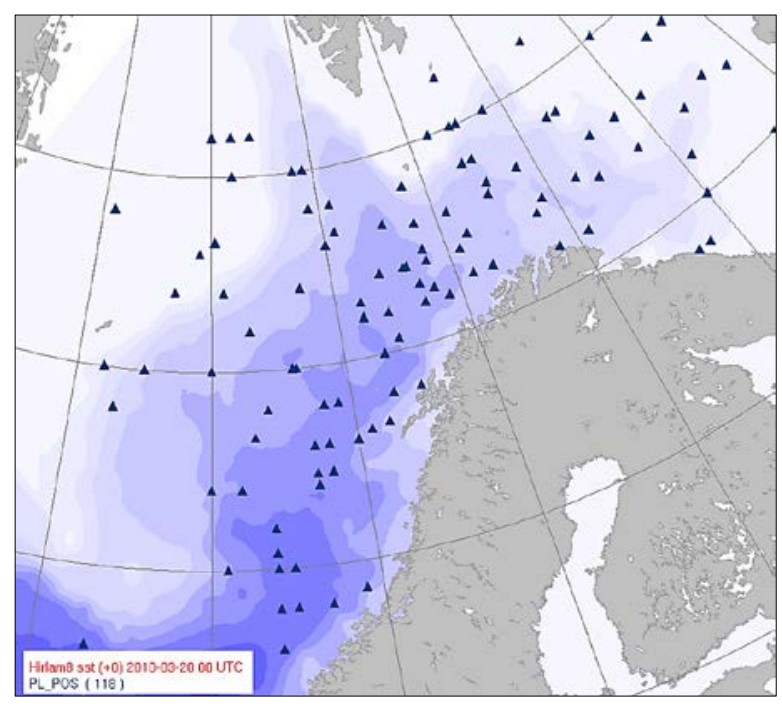

Figure 18. Geographical distribution of polar low pressure over the Barents and Norwegian Seas form 1999 to 2010 (Source: Norwegian Meteorological Institute) 


\subsubsection{Effects of polar low pressures on plant RAM performance}

The impact of polar low pressures on RAM performance of O\&G platforms and operations, are mainly those in common with strong winds, high waves, low temperatures, snow, and icing events. However, such effects can be intensified during the short period of the occurrence of polar low pressures. In this regard, platform or vessel stability, reliability of structural elements critical operations such as crane operations, workover operations, and flowline or pipeline installations are negatively affected by polar low pressures.

From the viewpoint of safety and environmental care, weather and meteorological conditions developed by polar low pressures can pose technical challenges or delays in escape, evacuation, and rescue efforts. Degraded visual environment because of possible associated snowstorms can intensify such challenges and threaten their successfulness. Helicopter operations for rescue purposes or scheduled crew transfers may be delayed for safety concerns. Implementation of oil spill removal techniques may be interrupted due to storms, high waves and strong winds. Such delays in containment and removal of spilt oil increase the extent of damage to the sensitive Arctic environment.

Moreover, considering the difficulties in the prediction of polar low pressures (ISO, 2010), maintenance activities, delivery of spare parts by offshore supply vessels, and offloading operations, are subjected to delays until a safe window-of-operation is achieved. Such circumstances add to the operation downtimes, cost, and reduced plant availability.

\subsection{Sea ice and icebergs}

\subsubsection{Sea ice}

Sea ice distribution and extension in the Barents Sea is mainly governed by the flow of different water masses including warm Atlantic and cold Arctic waters (see Figure 13) (Løset et al., 1999). However, according to the drifting patterns of sea ice floes and icebergs, both wind and sea current are governing drag forces, which determine the drifting speed and direction (Løset and Carstens, 1996; Løset et al., 1997; Marchenko et al., 2011). The maximum ice extent in the southern Barents Sea occurs in March, while its minimum extent happens in September and October (Løset and Carstens, 1996; Løset et al., 1999). Northern and northwestern parts of the Barents Sea are generally covered by ice during summer. The ice originated in the northern and northeastern parts drifts into the central Barents Sea, where ice of local origin exists once in three or four years (Løset et al., 1999).

Figure 19 shows the maximum limit of ice extent in the Barents Sea, based on the return period of 10, 50, and 100 years. Considering the 100-year return period, although the oil and gas fields in the Russian Barents Sea are located in the ice-covered area, none of the Norwegian fields of Goliat, Snøhvit, and Johan Castberg experience such sea ice conditions. However, considering the given extreme sea ice limit with a return period of 10000 years in Norwegian Standard N003 (NORSOK, 2007), the factor of sea ice must be taken into account in the design and operation of these fields. It should be noted that future O\&G exploration and production operations in northern parts of the Barents Sea are subjected to the sea ice. 


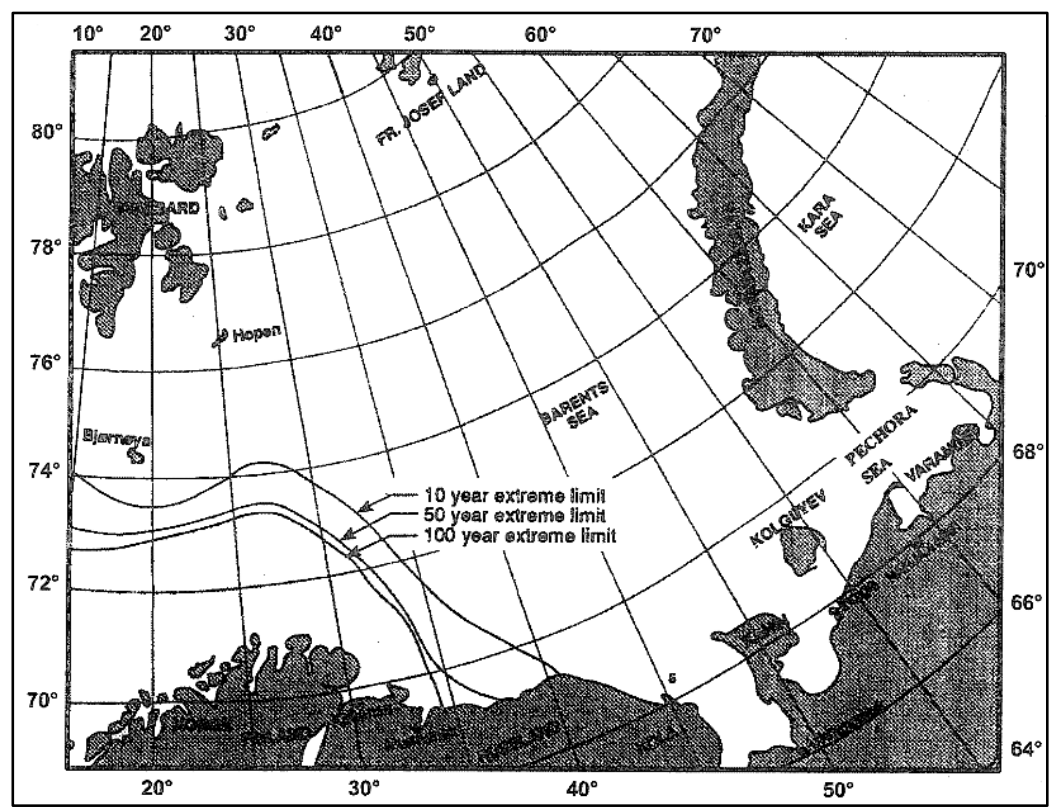

Figure 19. 10, 50, and 100 year extreme ice extent limit in the Barents Sea (Løset et al., 1997)

Since multi-year ice seldom appears in the western Barents Sea, the dominant ice in this area is first-year ice, whose thickness increases in winter and reaches its maximum in spring or early summer. Thickness of $1.8 \mathrm{~m}$ for the first-year and 3-5 $\mathrm{m}$ for the multi-year ice are recorded in the Barents Sea. Drifting of sea ice can result in first- and multi-year ice ridges. In most cases, ridges cover 30-50\% of the northern Barents Sea, with the most frequent maximum sail of about $2 \mathrm{~m}$ during the first half of the year, and then $1 \mathrm{~m}$ later on. Their frequency is ranging from 1 to 6 ice ridges per kilometre in early winter, and about 9 during disintegration period (Løset et al., 1999).

There are various ice floes of different sizes and masses in transition area between open sea and continuous ice cover, also known as marginal ice zone. Multi-year ice flows of $1 \mathrm{~km}$ in diameter have been observed near Hopen Island in 1989. Dimension of ice floes reduces at further distances from ice cover. The area between the ice floes is occupied by either brush ice or open water (Løset et al., 1999; Løset et al., 1997).

\subsubsection{Iceberg}

There is a large variation in number, size, and mass of the icebergs in the Barents Sea. Most of icebergs in the Barents Sea are regularly either drifting in from the Franz Josef Land archipelago or descending from glaciers on the eastern coast of Svalbard. They may also descend from the advection of ice masses from ice islands drifting in the Arctic Gyre (Løset and Carstens, 1993; Løset et al., 1999; Spring, 1993). However the biggest source of the Barents Sea icebergs is the Franz Josef Land archipelago that produces about $3.0 \mathrm{~km}^{3} /$ year of iceberg, half of which drifts directly to the Barents Sea along with Arctic water masses (Løset et al., 1999; Løset et al., 1997).

Influx of Arctic waters brings the ice floes and icebergs form the northeastern Barents Sea towards southwest. Due to the effects of warm Atlantic waters flowing from southwest towards north and northeast, most of these icebergs are either melted or captured around the Hopen Island, or drifted northwards around the west coast of Svalbard (Marchenko et al., 
2011). However, considerable numbers of icebergs have been also observed on the coast of East Finnmark in 1881 and in 1929 (NORSOK, 2007). Some of them have been observed in the western parts, south of Bjørnøya (Løset et al., 1999; Løset et al., 1997).

\subsubsection{Effects of sea ice on plant RAM performance}

Various types of sea ice such as first-year of multi-year ice, multi-year or first-year ridges, managed and unmanaged ice, etc. with different mechanical and geometric properties, in combination with their drifting speeds and directions pose different ranges of loads on structures. Global ice load, which is an integrated effect of local ice loads, governs the overall performance of structures (fixed and floating drilling and production platforms, icebreakers, supply vessels, and oil tankers) in ice.

In floating structures, the main concern may be riser damage either due to the direct loads from ice or loss of station-keeping system caused by horizontal ice loads. Motions of a moored vessel or platform in ice are strongly dependent on the performance of mooring system. Amount of force exerted on mooring lines greatly depends on the ice thickness and its drifting speed, in a way that thicker ice with lower drifting speed exerts higher forces (Li et al., 2008; Zhou et al., 2012). In this regard, one should also consider the interrelated effects of sea ice floes as well as wind and current speeds and directions (ISO, 2010). Although the hull damage is a crucial part of the structural reliability of the installation, mooring system is most likely designed in a way that mooring lines will fail before any sever hull damage occurs (Eik, 2011).

In the Barents Sea, installing gravity-based structures is limited to southwestern parts, where hydrocarbon fields are located in shallow waters. For instance, Prirazlomnoye platform, which is a steel caisson containing production and storage facilities, is located $57 \mathrm{~km}$ offshore from Varandey, Russia, at a depth of approximately 20 metres and is designed to operate in severe sea ice conditions (see Figure 20) (Moe and Rowe, 2008). Design of such bottomfounded structures must take into account both the global ice loads and ice pile-up around the structure or between the platform legs. Ice pile-up around a Prirazlomnoye caisson structure and between the legs of a jacket platform in the Bohai Sea in China, are depicted in Figures 20 and 21, respectively. The amount of sea ice accumulation and its resulting forces on the structure depend on the ice thickness, its drifting speed, distance between platform legs, haul shape and design characteristics (Zhang and Yue, 2011).

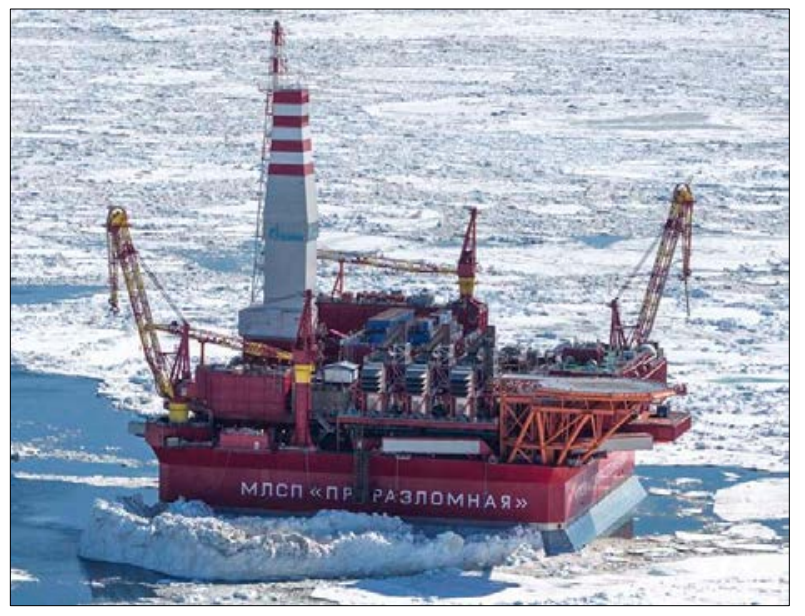

Figure 20. Sea ice pile-up around Prirazlomnoye caisson structure (source: Gazprom Neft Shelf LLC) 


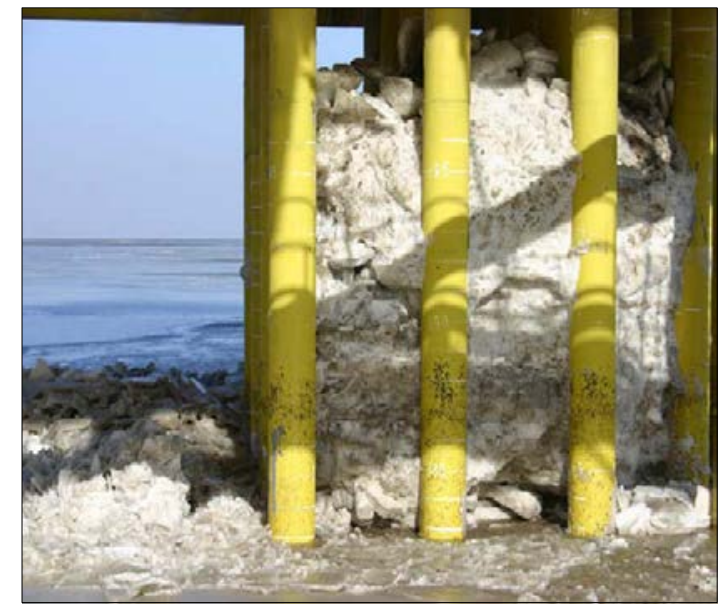

Figure 21. Sea ice pile-up between the platform legs in the Bohai Sea (Zhang and Yue, 2011)

Offshore structures, especially bottom-founded ones, in ice-covered areas need to withstand not only the static ice loads, but also the dynamic ice forces, which may result in structure vibration. The level and period of vibrations depend on the ice thickness, drifting speed, its mechanical properties, as well as failure modes of ice against the structure (Tuomo, 1994; Zhang and Yue, 2011). For instance, twenty vibration events in a single winter have been recorded for a caisson structure in Bohai Sea in China, which the longest steady-state vibration lasted for 15 minutes (Zhang and Yue, 2011).

The main issue arising from structure vibration is intensive shaking of the deck, which may cause uncomfortable and even hazardous working conditions for the crew and thus degrade human performance and accelerate human error rate. This can result in extended active repair times and thus additional downtimes should maintennace activities take palce. Platfrom vibration may also decrease equipment reliabiltiy by, for instance, inducing fatige failure. Falling of objects due to significnt shaking of platfrom can deteriorate operational safety and harm the crew. Liquefaction problems in the steel caisson structures due to vibration can threaten the structural reliability of the whole platform. A case in point is the sand liquefactions in Molikpaq steel caisson structure in the Beaufort Sea because of the vibration induced by dynamic ice loads (Wright and Timco, 1994; Zhang and Yue, 2011).

In terms of its impact on equipment maintainability and operation downtime, sea ice can contribute to logistic delays by increasing cruising time of offshore supply vessels in icecovered sea. This is of especial concern if maintenance activities are on hold due to lack of spare parts. Offloading operations may take longer time and be interrupted by significant forces exerted by sea ice. This consequently adds to the logistic delay and thus operation downtime and cost.

Loss of station-keeping systems due to lateral forces on platform or mooring system exerted by sea ice can threaten the safety of crew and wellbore (i.e., loss of wellbore). It may result in loss of well control and lead to devastating consequences such as explosions and huge oil spills. Another important safety factors for offshore operations is the evacuation of crew by life rafts and rescue operations by boats and vessels, which can be a challenging task in iceinfested waters. 


\subsubsection{Effects of icebergs on plant RAM performance}

One of the most critical challenges for O\&G offshore operations posed by icebergs are the risk of platform or vessel collision by icebergs. Figure 22 shows the limit for collision with icebergs with an annual probability of exceedance of $10^{-2}$ (solid line) and $10^{-4}$ (dotted line) in the Barents Sea. Considering the return period of 10000 years for iceberg collision, one must consider the iceberg collision risk while designing and operating in the western and southwestern Barents Sea, around Bjørnøya.

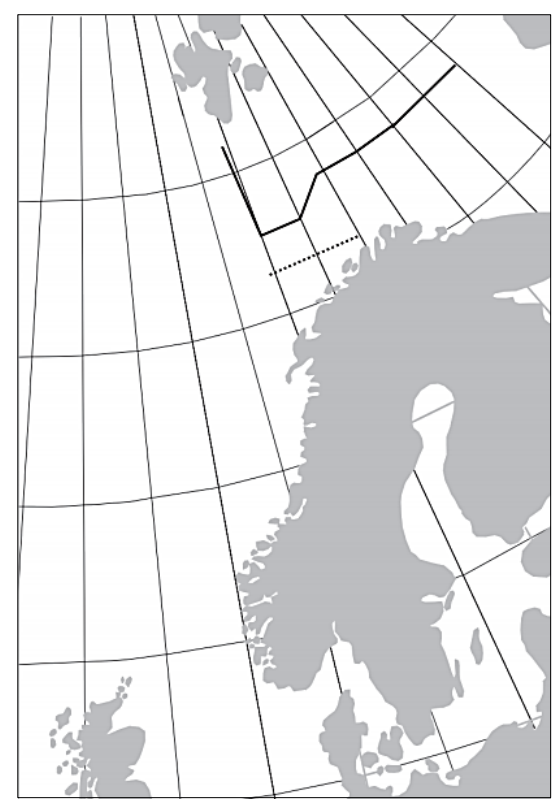

Figure 22. Limit for collision with icebergs with an annual probability of exceedance of $10^{-2}$ (solid line) and $10^{-4}$ (dotted line) (NORSOK, 2007)

The impact energy of an iceberg collision is a function of its mass and drifting speed. Depending on the amount of impact energy and collision direction, an iceberg collision can result in loss of station-keeping systems, production loss, operational downtimes, loss of wellbore, and enormous damage to the structure haul or legs. It can also contribute to creating hazardous safety situations for crew and potential failures of equipment units. Considering the 10,000-year return period for iceberg impact energy suggested by Norwegian Standard N-003 (NORSOK, 2007), Eik and Gudmestad (2010) estimated an impact energy of 85 MJ in Stockman region in southeastern Barents Sea. Designing a platform that can withstand such an amount of energy may not be practical and cost-effective. Therefore, adequate iceberg management strategies are required to reduce the risk of iceberg collision.

Icebergs can damage O\&G subsea installations such as pipelines, flowlines, wellheads, manifolds, etc., due to a process called "seabed gauging”. Seabed gauges, which occur when the keel of icebergs or ice ridges drifts into the seabed, vary in their length, width, and depth. Gouge marks can reach many kilometres in length and up to $5 \mathrm{~m}$ in depth, although most of them are less than $1 \mathrm{~m}$ deep (Barrette, 2011). Production loss, operational downtimes, considerable oil spill, and severe environmental damage are among the possible consequences of subsea installation failures due to seabed gauging by icebergs. 


\subsection{Fog, darkness, poor visibility, and plant RAM}

\subsubsection{Fog}

Fog is defined as suspended water droplets or ice particles near the Earth's surface that can lead to a reduction of horizontal visibility below $1 \mathrm{~km}$ (Gultepe et al., 2007; Holton et al., 2002). Fog particles, typically 5 to $50 \mu \mathrm{m}$ in diameter, form due to supersaturation by cooling, moistening and mixing of near surface air parcels of different temperatures (Gultepe et al., 2007). Although fogs do not last for very long, sometimes their duration can reach as long as $72 \mathrm{~h}$ (Przybylak, 2016). In the Barents Sea, the maximum duration of fog is observed in coastal regions and around islands in the western parts during summer (Proshutinsky et al., 1999).

Arctic fogs are divided into four main types of advection fog, radiation fog, steam fog or Arctic smoke, and ice fog (Przybylak, 2016), among which advection fog is the most common, especially in the Arctic Ocean and seas. Advection fogs occur mainly in summer, particularly from June to September, when relatively warm and moist air flows over a cold surface. In this regard, although southeastern Barents Sea and Kara Sea have favourable conditions for advection fog formation, the flow of warm Atlantic waters reduces the frequency of the formation of advection fog in Norwegian parts of the Barents Sea (Bryazgin and Dementyev, 1996; Gultepe et al., 2007; Przybylak, 2016).

The fogs in the Arctic very often correlate with ice concentration, wind direction, and wind speed (Proshutinsky et al., 1999). Most of fog events are observed with small wind speeds of $0-7 \mathrm{~m} / \mathrm{s}$ (Proshutinsky et al., 1999), although formation of advection fogs under wind speeds of $10 \mathrm{~m} / \mathrm{s}$ have been reported (Przybylak, 2016). Formation of fogs over ice-infested waters, among other factors, depends on ice concentration (Bryazgin and Dementyev, 1996; Proshutinsky et al., 1999; Przybylak, 2016). Frequency of fog occurrence increases with ice concentration for ice concentrations of less than 90\% (Proshutinsky et al., 1999). The highest frequency of fogs occurs over sea with a 70-90\% ice cover (Przybylak, 2016).

Spatial distribution of the number of days with fogs per month, season, or year is one of the most important characteristics of fog. Fog formation is common in summer with the highest frequency of $65-80 \%$. This is because air is very close to a point of saturation by water vapour and thus a small decrease in temperature is enough for fog formation. However, the frequency reduces in winter to about to $5-10 \%$ due to low absolute humidity of water masses and a low number of condensation particles (Proshutinsky et al., 1999; Przybylak, 2016). Fog is observed most often in the Arctic basin and over the Arctic seas with an average annual number of days with fog of 80 to 100. The highest number of days with fog is about 140 days per year that can occur in the central parts of the Arctic (Bryazgin and Dementyev, 1996; Przybylak, 2016).

In the Barents Sea, fog occurs mainly during summer and autumn (May to September), and may last for several days over large areas. For instance, Figure 23 shows a satellite image of fog covering a large part of the Barents Sea. While in northern parts of the Barents Sea, fogs may occur for about 80 days per year on average, they have a mean occurrence frequency of less than 10 days per year in southern areas. Frequency map of fogs over Arctic seas in July is depicted in Figure 24. As can be seen, the number of days with fogs in July over the Barents Sea varies from 5-10 days in southern regions to about 20-25 days in northern parts (Przybylak, 2016). However, such estimations are associated with high uncertainties, and in general, there 
is a significant lack of knowledge on the high-resolution frequency of occurrence, distribution, strength, and duration of fog in different locations of the Barents Sea (Syversen et al., 2015).

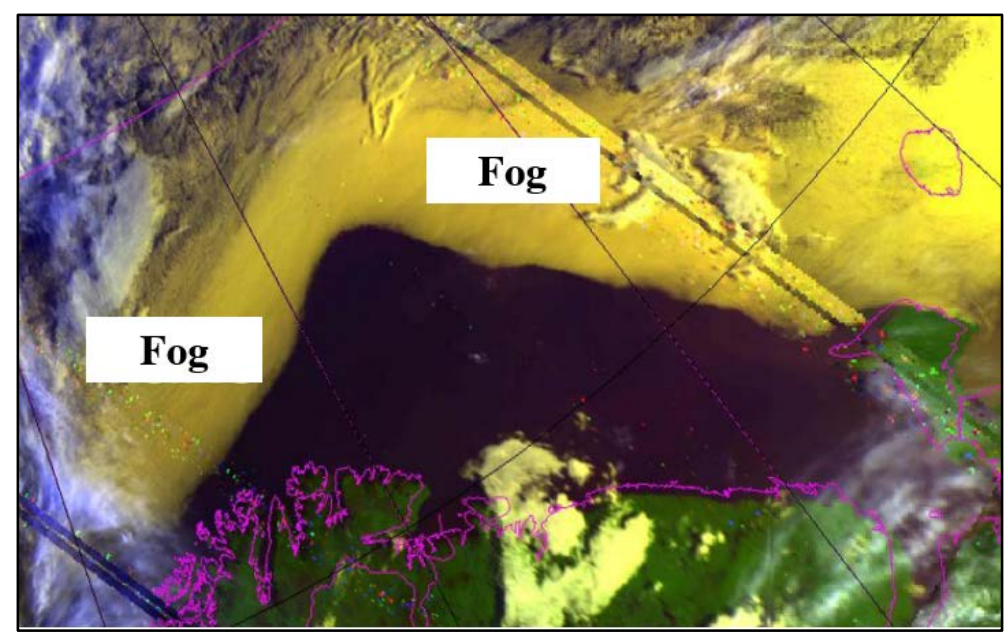

Figure 23. A satellite image of fog over the Barents Sea (Source: Norwegian Meteorological Institute)

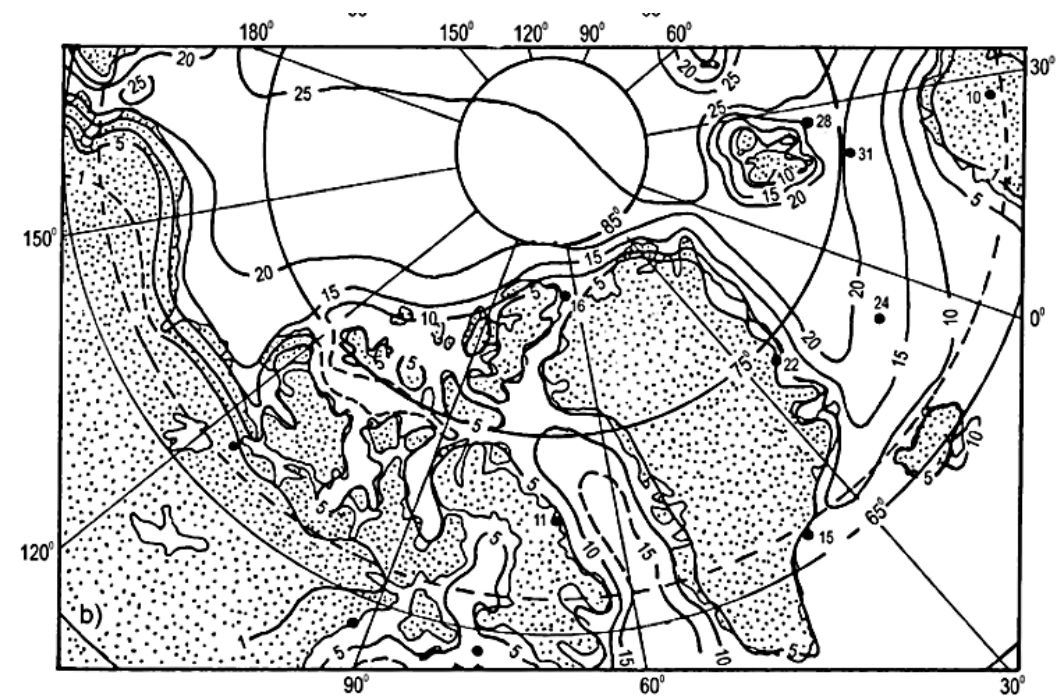

Figure 24. Average number of days with fog for July; black solid circles represent the maximum number of days with fog (Przybylak, 2016)

\subsubsection{Darkness}

Summer and winter seasons in the Arctic are characterised by midnight suns and polar nights, respectively, of which the latter refers to the periods with a complete absence of daylight. Relative positions of the sun and earth, and the site on the earth determine the length of complete darkness periods when sun goes below the horizon during winters. The duration of winter darkness can be calculated at a given location for a given time of the year. Alternatively, as shown in Figure 25, some charts present such information directly based on the location latitude and calendar date. Using available charts, Table 2 presents the darkness periods for Hopen Island and Bjørnøya, as well as for several fields in the Norwegian and Russian Barents Sea. It should be noted, depending on the location latitude, there is some useable illumination for a couple of hours due to the reflection of lights (i.e., twilight) even at continuous darkness periods (Crory, 1991; Freitag and McFadden, 1997). 


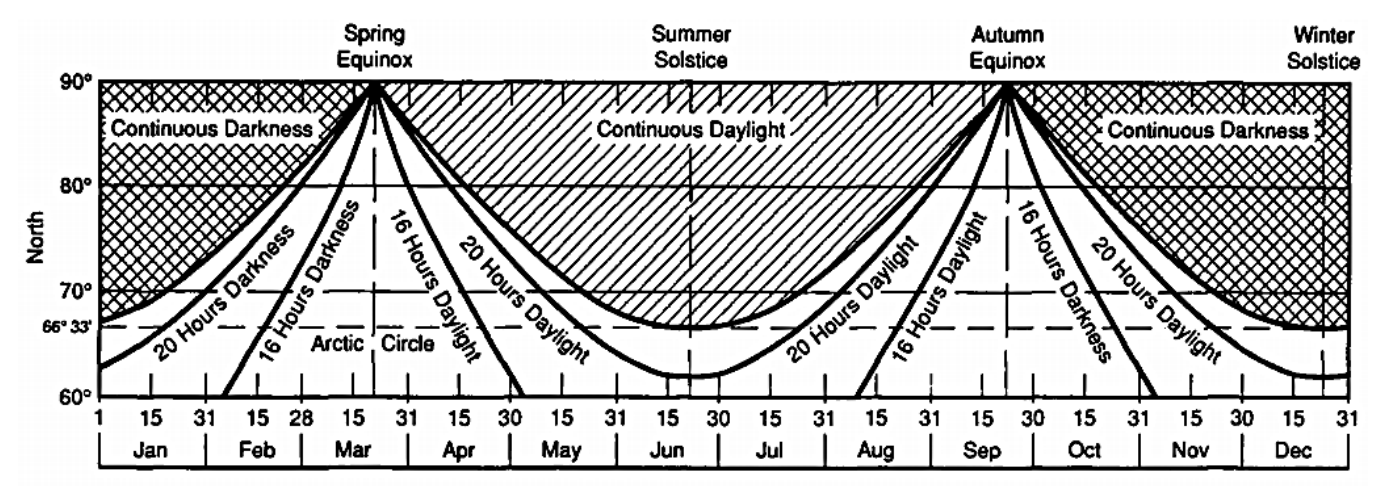

Figure 25. Duration of daylight and darkness for northern latitudes (Crory, 1991)

Table 2. Darkness periods in Barents Sea regions (data from: www.yr.no)

\begin{tabular}{|l|l|l|l|}
\hline Place & \multicolumn{2}{|l|}{ Darkness Period } & Number of Polar Nights \\
\hline Hopen Island & 31 Oct. & 10 Feb. & 102 \\
\hline Bjørnøya & 07 Nov. & 04 Feb. & 89 \\
\hline Shtokmanskoye Field & 13 Nov. & 30 Jan. & 79 \\
\hline Johan Castberg Field & 14 Nov. & 28 Jan. & 76 \\
\hline Snøhvit Field & 17 Nov. & 24 Jan. & 69 \\
\hline Goliat Field & 19 Nov. & 23. Jan & 66 \\
\hline
\end{tabular}

\subsubsection{Poor visibility}

The factor of poor visibility is a concern for Arctic regions throughout the year. Horizontal visibility in Arctic waters greatly depends on darkness, fog, snowstorm, and rain (Proshutinsky et al., 1999).

In summer seasons, fogs form over Arctic Ocean once Arctic sea ice breaks up. On a common basis, the thickness of polar fog is 20-100 m over ice-free waters during relatively calm weather in summer (Sakshaug et al., 2009). By definition, fog can reduce horizontal visibility to less than $1 \mathrm{~km}$ (Gultepe et al., 2007; Holton et al., 2002). Reduction in visibility occurs due to the presence of water droplets or ice crystals making an object undistinguishable to a distant observer, and thus depends on liquid water content of fogs (Kumai, 1973). In the Barents Sea, the annual number of days with a horizontal visibility of less than $1 \mathrm{~km}$ due to fog is about 80-130 days (ISO, 2010).

On the other hand, during short days and polar nights, poor visibility if often compounded by snowstorms or ice fogs. During a snowstorm, which happens with wind speeds of greater than $8 \mathrm{~m} / \mathrm{s}$ and air temperatures of less than $0^{\circ} \mathrm{C}$ (Proshutinsky et al., 1999), horizontal visibility reduces to below 2 or $2.5 \mathrm{~km}$ (ISO, 2010; Proshutinsky et al., 1999). A severe case is known as "whiteout", in which the atmosphere down to the very surface is filled with snow or ice crystals as low cloud layer that considerably reduces horizontal visibility (Freitag and McFadden, 1997). In the Barents Sea, the average number of days in a year with a visibility of less $2 \mathrm{~km}$ due to snowstorms ranges from 80 to 130 (ISO, 2010).

\subsubsection{Effects of darkness, fog, and poor visibility on plant RAM performance}

Reduced visibility and darkness can be considered as a threatening or dangerous factor for various kinds of human activity, primarily by increasing the chances of judgement errors and thus raising the probability of accidents (Bryazgin and Dementyev, 1996; Holton et al., 2002). 
The severity of such situations is often intensified by human being's ocular inability to distinguish objects given limited brightness and contrast that occur with fogs (Holton et al., 2002). In this regard, darkness and poor visibility can negatively affect the reliability of some offshore operations such as crane and helicopter operations. With respect to reliability, one should also take into account the accelerating effects of fogs on atmospheric corrosion (Bryazgin and Dementyev, 1996; King, 2011).

Helicopter traffic and operations such as medical evacuation, search and rescue, and crew transfer, are at risk during winter and summer periods with degraded visual environment (Syversen et al., 2015). Analysis of previous accidents in offshore helicopter operations shows that helicopters flying at night are involved in fatal accidents 15 times more frequently than in daytime (Nascimento et al., 2012). Figure 26 shows helicopter fatal accident rates during daytime and night. Impairment of both human visual perception and decision-making in degraded visual environment were identified as the most important cause of the increased fatal accident rate at night. Such accident frequencies are expected to increase during Arctic winter periods due to snowstorms and ice fogs.

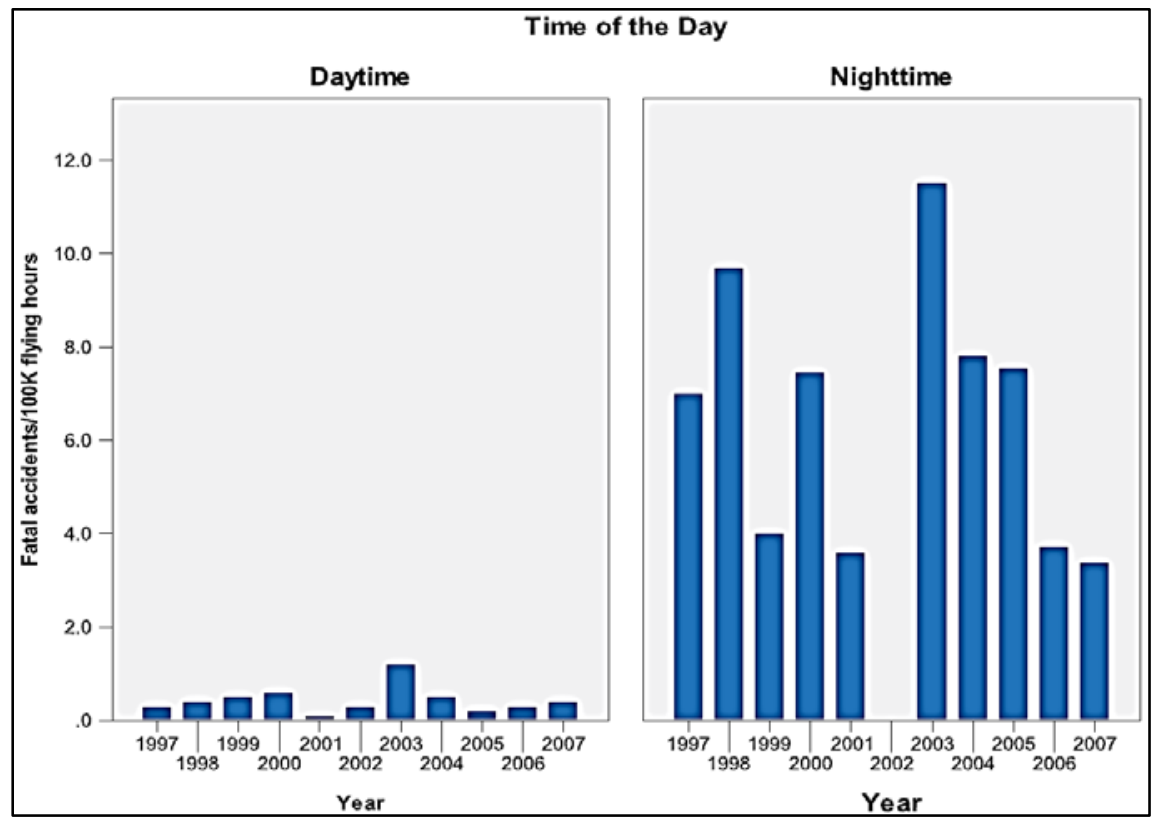

Figure 26. Fatal accident rates for offshore helicopters at nighttime and daytime (Nascimento et al., 2012)

Darkness reduces both the actual efficiency of workers and their motivation and interest in their tasks (Freitag and McFadden, 1997). This, consequently, can increase failure probabilities or safety-concerned situations due to elevated human error rate. It can also extend active repair times and thus reduce plant availability. In this regard, at worksites, artificial light is necessary when most of the day is dark. However, producing light bulbs, which are able to withstand the long and cold winter periods with an effective life has been a challenge for Arctic applications (Markeset et al., 2015). Under limited visibility, vessels can lose a channel or break convoy motion, especially in ice-infested waters. Shipping operations are stopped or slowed when visibility is as low as 0.25 mile $(0.4023 \mathrm{~km})$ (Holton et al., 2002). Release of stuck ships or reformation of a convoy take time that consequently reduces the efficiency of 
commercial navigations (Proshutinsky et al., 1999). In this regard, darkness and poor visibility can reduce plant availability by increasing logistic delays if spare parts are required.

From the viewpoint of safety and environmental impact, darkness and reduced visibility affect the efficiency of mechanical recovery of oil spills, as it will be challenging to find the thickest oil layer or to monitor oil losses from booms and skimmers (Naseri and Barabady, 2015a). Different phases of escape, evacuation, and rescue operations are affected by polar darkness and poor visibility, as well. For instance, Yun and Marsden (2010) predicted that the probability of success of evacuation and rescue by helicopter reduces by $20 \%$ in situations with poor visibility.

In summary, data on the frequency of clear vs cloudy days, darkness periods, hours of daylight, frequency of fog and snowstorm occurrence are important to flying, shipping, and outside works (Crory, 1991; ISO, 2010). However, an insufficient number of weather stations are located within Arctic Ocean and seas (Crory, 1991).

\subsection{Remoteness, less-developed infrastructure and plant RAM}

\subsection{Remoteness and less-developed infrastructure}

In general, Arctic areas are sparsely populated and thus the infrastructure is underdeveloped (Freitag and McFadden, 1997; Larsen and Markeset, 2007). Moreover, Arctic fields, including those in the Norwegian Barents Sea, are usually located within long distances from suppliers, manufacturers, and well-stablished ports. Compared to normal-climate regions, there are few weather stations in the Arctic and thus weather data to predict and make precise weather forecasts for offshore regions are limited (Gudmestad and Karunakaran, 2012; Kayrbekova et al., 2011; Zaki, 2015). The logistic and emergency supports for O\&G operations taking place in the Norwegian Barents Sea are mainly based on the facilities and infrastructure available in Finnmark County. Such facilities, compared to southern parts of Norway, where O\&G industry operates in the North Sea, are considerably limited. A detailed description on the current infrastructure level of Northern Norway regions is given in (Eger et al., 2012; Zaki, 2015).

\subsubsection{Effects of remoteness and infrastructure level on plant RAM performance}

Less-developed infrastructure and remote distances from suppliers and market can affect overall support strategies and logistics, such as transportation of equipment, modules, people, spare parts and inventory management. This can result in extended plant downtimes due to the unavailability of materials, tools, spare parts, and personnel (Kayrbekova et al., 2011). Such shortcomings are aggravated and thus require more time and planning if once considers the negative impact of harsh weather conditions, less availability of weather-window, lack of sufficient competence, experience, and knowledge (Larsen and Markeset, 2007).

Additionally, satellite coverage from geostat reduces in latitudes more than $70^{\circ}$ and even not available beyond $83.1^{\circ}$. Such a lack of satellite coverage and thus telecommunication means pose limitations on communication and data transfer for vessels and mobile units. It negatively affects transferring real-time technical advice and remote support to the operation and maintenance crew on-board. In safety emergencies, providing medical advice from nearby hospitals will be limited or unavailable. The effectiveness of search and rescue operations will be reduced as well (Larsen and Markeset, 2007). 


\section{Concluding remarks}

RAM is used as one of the key indicators to predict, analyse, and assess the performance of O\&G plants. Among other factors, RAM depends on operating conditions in such a way that harsh environmental conditions of the Arctic offshore can adversely affect plant RAM performance. Such severe conditions coupled with sensitive Arctic environment and wildlife give rise to the importance of analysing RAM performance of Arctic offshore O\&G facilities.

Employing RAM models and data corresponding to normal-climate regions may lead to a great deal of uncertainty for Arctic offshore applications. It is mainly due to the exclusion of the impact of Arctic environmental conditions and their year-round variations. In this regard, models and methodologies should be developed that analyse the performance of O\&G plants in the Arctic, accordingly. For instance, to develop a spare parts delivery model, one should account for the effects of continuous parameters of the weather (e.g., air temperature and wind speed) on plant RAM. In addition, such a model should be able to reflect upon the impact of discrete meteorological phenomena (e.g., polar low pressures) and sea state (e.g., sea ice and iceberg drift) on lead-time and possible supply delivery delays. To this aim, identification of the elements of Arctic offshore operating conditions and understanding their potential effects play a key role. In this paper, the environmental conditions of the Arctic offshore, which are specific to the Barents Sea, coupled with their impacts on the performance of O\&G facilities and operations are reviewed and discussed thoroughly.

One of the shortcomings in Arctic offshore RAM analysis is limited experience and lack of adequate historical reliability data that can represent the effects of operating conditions on plant RAM. Expert judgement concept may be used as an alternative to tackle such a problem. Models and methodologies should then be developed aiming at the integration of expert data with reliability data collected in normal-climate regions. Additionally, reliability testing (e.g., accelerated life testing) may be used to estimate the reliability of equipment units under varying Arctic operating condition.

However, analyses made using the data collected through expert judgement processes or reliability testing are associated with epistemic uncertainties arising from the gap of knowledge on plant RAM performance under realistic Arctic offshore conditions. Furthermore, there is a randomness in Arctic weather and meteorological parameters (e.g., icing storms and polar low pressures), which contributes to aleatory uncertainties that are irreducible. Making decisions in the light of such uncertainties and costly operations should then be given an utmost attention. This is highlighted by the factors of remoteness, lack of appropriate infrastructure, and waiting for weather-windows, which greatly affect commissioning, decommissioning, logistic supports, installation activities, oil spill combat strategies, escape, evacuation, and rescue operations, crew transfer, etc.

It is suggested that O\&G companies, operating in the Arctic, develop shared databases by not only collecting reliability data for various equipment units of Arctic offshore O\&G facilities, but also by recording the key parameters of environmental conditions in plant locations. Guidelines and standards should be developed specific to RAM analysis of plants operating in the Arctic offshore. Sharing knowledge can effectively compensate for the lack of experience in the long-term in these regions. 


\section{Acknowledgements}

We would like to thank the Research Council of Norway for funding this research. We also thanks the comments given by Prof. Alfred Hanssen and Dr. Abbas Barabadi on this paper.

\section{References}

Artiba, A., Riane, F., Ghodrati, B. and Kumar, U., 2005. Reliability and operating environment-based spare parts estimation approach: a case study in Kiruna Mine, Sweden. Journal of Quality in Maintenance Engineering, 11(2): 169-184.

Azar, J.J. and Samuel, G.R., 2007. Drilling engineering. PennWell Books, Tulsa.

Baller, H., 1983. Rig winterization to allow year-round drilling off northern Norway. Oil \& Gas, 81(31): 71-75.

Baller, H. and Friedberg, R., 1984. Statoil develops next-generation arctic rigs. Oil \& Gas, 82(51): 82-84.

Barabadi, A., Barabady, J. and Markeset, T., 2011. A methodology for throughput capacity analysis of a production facility considering environment condition. Reliability Engineering \& System Safety, 96(12): 1637-1646.

Barabadi, A., Gudmestad, O.T. and Barabady, J., 2015. RAMS data collection under Arctic conditions. Reliability Engineering \& System Safety, 135(0): 92-99.

Barabadi, A. and Markeset, T., 2011. Reliability and maintainability performance under Arctic conditions. International Journal of System Assurance Engineering and Management, 2(3): 205-217.

Barabady, J. and Kumar, U., 2008. Reliability analysis of mining equipment: A case study of a crushing plant at Jajarm Bauxite Mine in Iran. Reliability Engineering \& System Safety, 93(4): 647-653.

Barabady, J., Markeset, T. and Kumar, U., 2010. Review and discussion of production assurance program. International Journal of Quality \& Reliability Management, 27(6): 702-720.

Barrette, P., 2011. Offshore pipeline protection against seabed gouging by ice: An overview. Cold Regions Science and Technology, 69(1): 3-20.

Bluestein, M. and Quayle, R., 2003. Wind Chill. In: J.R. Holton, J.A. Curry and J.A. Pyle (Editors), Encyclopedia of Atmospheric Sciences. Academic Press, Oxford, pp. 2597-2602.

Bryazgin, N.N. and Dementyev, A.A., 1996. Meteorological Hazards in the Russian Arctic. Hydrometeorological Publishing House, St. Petersburg.

Bulakh, M., Zolotukhin, A.B. and Gudmestad, 0.T., 2011. Potential For Oil And Gas Projects In The New Oil And Gas Province Shared Between Russia And Norway, SPE Arctic and Extreme Environments Conference and Exhibition, 18-20 October, Moscow, Russia.

Caenn, R., Darley, H.C.H. and Gray, G.R., 2011a. Chapter 5 - The Rheology of Drilling Fluids. In: R. Caenn, H.C.H. Darley and G.R. Gray (Editors), Composition and Properties of Drilling and Completion Fluids (Sixth Edition). Gulf Professional Publishing, Boston, pp. 179-269.

Caenn, R., Darley, H.C.H. and Gray, G.R., 2011b. Chapter 10 - Completion, Reservoir Drilling, Workover, and Packer Fluids. In: R. Caenn, H.C.H. Darley and G.R. Gray (Editors), Composition and Properties of Drilling and Completion Fluids (Sixth Edition). Gulf Professional Publishing, Boston, pp. 477-533.

Caenn, R., Darley, H.C.H. and Gray, G.R., 2011c. Chapter 11 - Drilling Fluid Components. In: R. Caenn, H.C.H. Darley and G.R. Gray (Editors), Composition and Properties of 
Drilling and Completion Fluids (Sixth Edition). Gulf Professional Publishing, Boston, pp. 535-616.

Calixto, E., 2013. Gas and Oil Reliability Engineering. Gulf Professional Publishing, Boston.

Carstens, T., 1983. Special hazards in open waters at high latitudes. Cold Regions Science and Technology, 7(0): 293-295.

Carstens, T., 1985. Polar Lows - A Threat to Offshore Operations in Northern Waters, 8th International Conference on Port and Ocean Engineering under Arctic Conditions (POAC85), 7-14 September, Greenland.

CCPS, 2016. Process Equipment Reliability Database (PERD). American Institute of Chemical Engineers - Center for Chemical Process Safety, New York.

Center, N.S.W., 2011. Handbook of Reliability Prediction Procedures for Mechanical Equipmet. Naval Surface Warfare Center - Carderoc Devision, West Bethesda.

Crory, F.E., 1991. CRREL Report 19-21: Construction guidelines for oil and gas exploration in northern Alaska, USA Cold Regions Research and Engineering Lab (CRREL), Hanover, NH.

Crowley, J.D., 1988. Cold water effects upon marine operations, Proceedings OCEANS' 88 - A Partnership of Marine Interests. IEEE, 31 October - 2 November.

Deepwater Horizon Study Group, 2011. Final Report on the Investigation of the Macondo Well Blowout, Center for Catastrophic Risk Management (CCRM), University of California, Berkeley, USA.

Department of Defense, 1981. Military Standard MIL-STD-721C - Definitions of terms for reliability and maintainability. Department of Defense, Washington, DC.

Department of Defense, 1991. Military Handbook MIL-HDBK-217F - Reliability Predition of Electronic Equipment. Department of Defense, Washington D.C.

Doré, A.G., 1995. Barents Sea Geology, Petroleum Resources and Commercial Potential. Arctic, 48(3): 207-221.

Dutta, P.K., 1988. Behaviour of materials at cold regions temperatures - Part 1: Program rationale and test plan, US Army Engineer Research and Development Centre, New Hampshire.

Duval, B.C., 1975. Exploratory Drilling on the Canadian Continental Shelf,Labrador Sea, Offshore Technology Conference, 5-8 May Huston.

Ebeling, C.E., 2005. An Introduction to Reliability and Maintainability Engineering. Waveland Press, Long Grove.

Eger, K.M., Grimstad, H., Solberg, K.E., Barlindhaug, J., Pedersen, T. and Karlstrøm, R., 2012. Infrastruktur og logistikk ved petroleumsvirksomhet i Barentshavet sørøst, Ministry of Petroleum and Energy, Oslo.

Eik, K., 2011. Sea-ice management and its impact on the design of offshore structures. Cold Regions Science and Technology, 65(2): 172-183.

Eik, K. and Gudmestad, O.T., 2010. Iceberg management and impact on design of offshore structures. Cold Regions Science and Technology, 63(1-2): 15-28.

El-Reedy, M.A., 2012. Chapter 2 - Offshore Structure Loads and Strength. In: M.A. El-Reedy (Editor), Offshore Structures. Gulf Professional Publishing, Boston, pp. 23-91.

Fingas, M., 2011. Chapter 13 - Weather Effects on Oil Spill Countermeasures. In: M. Fingas (Editor), Oil Spill Science and Technology. Gulf Professional Publishing, Boston, pp. 339-426.

Freitag, D.R. and McFadden, T.T., 1997. Introduction to cold regions engineering. ASCE Press, New York. 
Frêne, J., Nicolas, D., Degueurce, B., Berthe, D. and Maurice, G., 1997. Tribology Series Volume 33, Hydrodynamic Lubrication - Bearings and Thrust Bearings. Elsevier, 27-46 pp.

Funk, C., 2012. Freezing Spray \& Ice Accretion on Vessels: A Comprehensive Study, National Conference On Undergraduate Research (NCUR), 29-31 March, Ugden, USA.

Gao, X., Barabady, J. and Markeset, T., 2010. An approach for prediction of petroleum production facility performance considering Arctic influence factors. Reliability Engineering \& System Safety, 95(8): 837-846.

Gao, Y. and Li, K., 2012. New models for calculating the viscosity of mixed oil. Fuel, 95(0): 431-437.

Gasson, J.R., Barth, T. and Genov, G., 2013. Comparison of the gas hydrate plugging potentials of a set of crude oils from the Norwegian continental shelf using chemometric decomposition of GC-FID data. Journal of Petroleum Science and Engineering, 102(0): 66-72.

Gudmestad, O.T., 1999. Characteristics of Offshore Climate Conditions and Associated Loading on Offshore Structures. In: O.T. Gudmestad et al. (Editors), Basics of offshore petroleum engineering and development of marine facilities with emphasis on the arctic offshore. Moskva Neft' i Gaz, Stavanger, Moscow, St. Petersburg, Trondheim.

Gudmestad, O.T. and Karunakaran, D., 2012. Challenges Faced by the Marine Contractors Working in Western and Southern Barents Sea, OTC Arctic Technology Conference, 3-5 December, Houston, Texas, USA.

Guest, P., 2005. Vessel Icing. Marines Weather Log, 49(3).

Gultepe, I., Tardif, R., Michaelides, S.C., Cermak, J., Bott, A., Bendix, J., Müller, M.D., Pagowski, M., Hansen, B., Ellrod, G., Jacobs, W., Toth, G. and Cober, S.G., 2007. Fog Research: A Review of Past Achievements and Future Perspectives. In: I. Gultepe (Editor), Fog and Boundary Layer Clouds: Fog Visibility and Forecasting. Birkhäuser Verlag AG, Basel, pp. 1121-1159.

Hamilton, L., 2004. The polar low phenomenon, Group for Earth Observation (GEO) Quarterly. The Independent Organisation for Weather Satellite and Earth Observation Enthusiasts, pp. 10-12.

Hasle, J.R., Kjellén, U. and Haugerud, 0., 2009. Decision on oil and gas exploration in an Arctic area: Case study from the Norwegian Barents Sea. Safety Science, 47(6): 832-842.

Hodgins, S.L.M. and Hodgins, D.0., 1991. Environmental Criteria for Canadian Waters: An Assessment of Data Resources and Design Requirements, Seaconsult Marine Research Ltd., Vancouver.

Holton, J.R., Curry, J.A. and Pyle, J.A., 2002. Encyclopedia of Atmospheric Sciences. Academic Press, London.

Homlong, E., Kayrbekova, D., Panesar, S.S. and Markeset, T., 2012. Assessing Maintenance Time, Cost and Uncertainty for Offshore Production Facilities in Arctic Environment. In: J. Frick and B.T. Laugen (Editors), Advances in Production Management Systems - Value Networks: Innovation, Technologies, and Management. Springer, Heidelberg, pp. 222-232.

Håbrekke, S., Hauge, S. and Onshus, T., 2013. Reliability Data for Safety Instrumented Systems. Trondheim, Sintef. 
IEC, 2004. IEC TR 62380 Reliability data handbook - Universal model for reliability prediction of electronics components, PCBs and equipment International Electrotechnical Commission (IEC), Geneva.

IEV, 2016. IEV 60050-192: International Electrotechnical Vocabulary (IEV)- Part 192: Dependability. International Electrotechnical Commission, Geneva.

ISO, 1994. ISO 8402:1994 - Quality management and quality assurance - Vocabulary. ISO, Geneva.

ISO, 2001. ISO 12494: Atmospheric Icing of Structures. ISO, Geneva.

ISO, 2005. ISO/DIS 19901-1: Petroleum and natural gas industries - Specific requirements for offshore structures - Part 1: Metocean design and operating considerations. ISO, Geneva.

ISO, 2008. ISO 20815: Petroleum, petrochemical and natural gas industries - Production assurance and reliability management. ISO, Geneva.

ISO, 2010. ISO 19906: Petroleum and Natural Gas Industries - Arctic Offshore Structures. ISO, Geneva.

Jamaluddin, A.K.M., Kalogerakis, N. and Bishnoi, P.R., 1991. Hydrate plugging problems in undersea natural gas pipelines under shutdown conditions. Journal of Petroleum Science and Engineering, 5(4): 323-335.

Jones, K.F. and Andreas, E.L., 2009. Sea Spray Icing of Drilling and Production Platforms, US Army Engineer Research and Development Centre, New Hampshire, USA.

Journée, J. and Massie, W., 2001. Offshore hydromechanics. TU Delft, Delft.

Kayrbekova, D., Barabadi, A. and Markeset, T., 2011. Maintenance cost evaluation of a system to be used in Arctic conditions: a case study. Journal of Quality in Maintenance Engineering, 17(4): 320-336.

Keane, B., Schwarz, G. and Thernherr, P., 2013. Electrical equipment in cold weather applications, Petroleum and Chemical Industry Technical Conference (PCIC). IEEE, 23-25 September, Chicago.

King, G.A., 2011. Atmospheric corrosion in cold regions. In: R.W. Revie (Editor), Uhlig's corrosion hanbook. John Wiley \& Sons, Hoboken, New Jersy.

Klett, T.R. and Gautier, D.L., 2009. USGS Fact Sheet 2009-3037: Assessment of undiscovered petroleum resources of the Barents Sea Shelf, U.S. Geological Survey (USGS), Reston.

Kulyakhtin, A., Løset, S. and Kollar, L., 2012. Small-scale Simulation of Seawater Icing in Natural Field Conditions, 21st IAHR International Symposium on Ice, 11-15 June, Dalian, China.

Kumai, M., 1973. Arctic fog droplet size distribution and its effect on light attenuation. Journal of the Atmospheric Sciences, 30(4): 635-643.

Kumar, R., Barabady, J., Markeset, T. and Kumar, U., 2012. Improving maintainability in extreme cold climatic conditions. International Journal of Performability Engineering, 8(5): 563-572.

Larsen, A.C. and Markeset, T., 2007. Mapping of operations, maintenance and support design factors in Arctic environments. In: T. Aven and J.E. Vinnem (Editors), Risk, Reliability and Societal Safety. Taylor \& Francis, London.

Li, G., Liu, X., Liu, Y. and Yue, Q., 2008. Optimum design of ice-resistant offshore jacket platforms in the Bohai Gulf in consideration of fatigue life of tubular joints. Ocean Engineering, 35(5-6): 484-493.

Liljestrom, J., 1985. Icing on Semisubmersible Platforms, Proceeding of International Workshop on Offshore Winds and Icing, 7-11 October, Halifax, Canada, pp. 313328. 
Loeng, H., 1991. Features of the physical oceanographic conditions of the Barents Sea. Polar research, 10(1): 5-18.

Lundqvist, J.-E. and Udin, I., 1977. Ice accretion on ships with special emphasis on Baltic conditions, Swedish Administration of Shipping and Navigation, Finish Board of Navigation, Norrköping, Sweden.

Løset, S. and Carstens, T., 1993. Production of Icebergs and Observed Extreme Drift Speeds in the Barents Sea, The 12th International Conferences on Port and Ocean Engineering under Arctic Conditions (POAC'93), 17-20 August, Hamburg, Germany.

Løset, S. and Carstens, T., 1996. Sea ice and iceberg observations in the western Barents sea in 1987. Cold Regions Science and Technology, 24(4): 323-340.

Løset, S., Shkhinek, K., Gudmestad, O.T., Strass, P., Michalenko, E., Frederking, R. and Kärnä, T., 1999. Comparison of the physical environment of some Arctic seas. Cold Regions Science and Technology, 29(3): 201-214.

Løset, S., Shkhinek, K., Strass, P., Gudmestad, O.T., Michalenko, E.B. and Kärnä, T., 1997. Ice Conditions in the Barents and Kara Seas, 16th International Conference on Offshore Mechanics and Arctic Engineering, 13-18 April, Yokohama, Japan.

Marchenko, A., Kvamstad, B., Fjørtoft, K., Hoyland, K. and Brazhnikov, D., 2011. Characteristics of ice drift in the western Barents Sea reconstructed by the data of ice trackers deployed on drifting ice and icebergs in 2008-2010, The International Conferences on Port and Ocean Engineering under Arctic Conditions (POAC11), 10-14 July, Montréal, Canada.

Markeset, T., Saeland, A., Gudmestad, O. and Barabady, J., 2015. Petroleum production facilities in Arctic operational environments. In: A. Bourmistrov, F. Mellemvik and A. Bambulyak (Editors), International Arctic Petroleum Cooperation: Barents Sea Scenarios. Routledge, London, pp. 184-203.

Matishov, G., Golubeva, N., Titova, G., Sydnes, A. and Voegele, B., 2004. Global International Waters Assessment - Barents Sea, GIWA Regional assessment 11, University of Kalmar, Kalmar, Sweden.

Misra, K.B., 2008. Handbook of Performability Engineering. Springer, London.

Moe, A., 2010. Russian and Norwegian petroleum strategies in the Barents Sea. Arctic Review on Law and Politics, 1(2): 225-248.

Moe, A. and Rowe, L., 2008. FNI Report 7/2008: Petroleum Activity in the Russian Barents Sea, Fridtjof Nansens Institute (FNI), Lysaker, Norway.

Mäkinen, T.M., Palinkas, L.A., Reeves, D.L., Pääkkönen, T., Rintamäki, H., Leppäluoto, J. and Hassi, J., 2006. Effect of repeated exposures to cold on cognitive performance in humans. Physiology \& Behavior, 87(1): 166-176.

Nascimento, F.A.C., Majumdar, A., Ochieng, W.Y. and Jarvis, S.R., 2012. A multistage multinational triangulation approach to hazard identification in night-time offshore helicopter operations. Reliability Engineering \& System Safety, 108(0): 142-153.

Naseri, M. and Barabady, J., 2015a. Performance of skimmers in the Arctic offshore oil spills. In: T. Nowakowski, M. Młyńczak, A. Jodejko-Pietruczuk and S. WerbińskaWojciechowska (Editors), Safety and Reliability: Methodology and Applications. CRC Press, London.

Naseri, M. and Barabady, J., 2015b. System-Reliability Analysis by Use of Gaussian Fuzzy Fault Tree: Application in Arctic Oil and Gas Facilities. Oil and Gas Facilities, 4(3): $1-11$. 
Naseri, M., Baraldi, P., Compare, M. and Zio, E., 2016. Availability Assessment of Oil and Gas Processing Plants Operating under Dynamic Arctic Weather Conditions. Accepted for publication in the Journal of Reliability Engineering \& System Safety. Nikiforov, S., Dunaev, N. and Politova, N., 2005. Modern environmental conditions of the Pechora Sea (climate, currents, waves, ice regime, tides, river runoff, and geological). In: H.A. Bauch, Y.A. Pavlidis, Y.I. Polyakova, G.G. Matishov and N. Koç (Editors), Pechora Sea Environments: Past, Present and Future. Berichte zur Polar-und Meeresforschung, Bremerhaven, Germany.

NORSOK, 2007. NORSOK Standard N-003 - Actions and Action Effects. Standards Norway (NORSOK), Lysaker, Norway.

Norwegian Meteorological Institutte, 2013. Polar low 6th of February 2012. Det Norske Meteorologiske Institutt.

NPD, 2013. The petroleum resources on the Norwegian continental shelf Norwegian Petroleum Directorate, Stavanger.

Obanijesu, E.O., Akindeju, M.K., Vishnu, P. and Tade, M.O., 2011. Modelling the Natural Gas Pipeline Internal Corrosion Rate Resulting from Hydrate Formation. In: E.N. Pistikopoulos, M.C. Georgiadis and A.C. Kokossis (Editors), Computer Aided Chemical Engineering. Elsevier, pp. 1160-1164.

OREDA Participants, 2009. Offshore Reliability Data Handbook 5th ed. OREDA Participants, Trondhim.

Osczevski, R. and Bluestein, M., 2005. The new wind chill equivalent temperature chart. Bulletin of the American Meteorological Society, 86(10): 1453-1458.

Parent, 0. and Ilinca, A., 2011. Anti-icing and de-icing techniques for wind turbines: Critical review. Cold Regions Science and Technology, 65(1): 88-96.

Proshutinsky, A.Y., Proshutinsky, T. and Weingartner, T., 1999. INSROP Working Paper No. 126 - Environmental Conditions Affecting Commercial Shipping on the Northern Sea Routes, International Northern Sea Route Programme, Lysaker.

Przybylak, R., 2016. The Climate of the Arctic. Springer, Cham.

Rasmussen, E.A. and Turner, J., 2003. Polar Lows - Mesoscale Weather Systems in the Polar Regions. Cambridge University Press, Cambridge.

Rausand, M. and Høyland, A., 2004. System reliability theory: models, statistical methods, and applications. John Wiley \& Sons, Hoboken.

Rudin, A. and Choi, P., 2013. Chapter 4 - Mechanical Properties of Polymer Solids and Liquids. In: A. Rudin and P. Choi (Editors), The Elements of Polymer Science \& Engineering (Third Edition). Academic Press, Boston, pp. 149-229.

Ryerson, C.C., 2008. Assessment of Superstructure Ice Protection as Applied to Offshore Oil Operations: Safety Problems, Hazards, Needs, and Potential Transfer Technologies, US Army Engineer Research and Development Center, New Hampshire, USA.

Ryerson, C.C., 2011. Ice protection of offshore platforms. Cold Regions Science and Technology, 65(1): 97-110.

Sakshaug, E., Johnsen, G.H. and Kovacs, K.M., 2009. Ecosystem Barents Sea. Tapir Academic Press, Trondheim.

Sasanuma, S. and Matsubara, K., 1995. Transition Phenomena of Lubricating Oils and Greases in a Low Temperature Range Examined by a Torsional Braid Analysis. In: D. Dowson, C. M. Taylor, T.H.C. Childs and G. Dalmaz (Editors), Tribology Series Volume 30. Elsevier, pp. 31-44.

Satter, A., Iqbal, G.M. and Buchwalter, J.L., 2008. Practical Enhanced Reservoir Engineering: Assisted With Simulated Software. Pennwell Books, Tulsa, USA. 
Singh, R., 2013. Chapter 7 - Material Properties in Low Temperature Environment. In: R. Singh (Editor), Arctic Pipeline Planning. Gulf Professional Publishing, Boston, pp. 75-88.

Spring, W.V., T. Jensen, H., 1993. Iceberg and Sea Ice Data Obtained in the Annual Expeditions of the Barents Sea Ice Data Acquisition Program (IDAP), The 12th International Conferences on Port and Ocean Engineering under Arctic Conditions (POAC'93), 17-20 August, Hamburg, Germany.

Stachowiak, G.W. and Batchelor, A.W., 2006. 2 - Physical Properties of Lubricants. In: G.W. Stachowiak and A.W. Batchelor (Editors), Engineering Tribology (Third Edition). Butterworth-Heinemann, Burlington, pp. 11-50.

Stapelberg, R.F., 2009. Handbook of reliability, availability, maintainability and safety in engineering design. Springer, London.

Syversen, T., Dinessen, F., Paaske, B.J., Ekeberg, O.-C., Hughes, N. and Kråkenes, T., 2015. Kartlegging av is- og snøforekomst i Barentshavet, inkludert risikovurderinger relatert til petroleumsaktivitet, SINTEF, Trondheim.

Toomey, R.M., Lloyd, M., House, D.J. and Dickins, D., 2010. The Ice Navigation Manual. Witherby Seamanship International Ltd, Edinburgh, UK.

Tuomo, K., 1994. Mitigation of Steady-State Vibrations Induced by Ice, Teh 4th International Offshore and Polar Engineering Conference 10-15 April, Osaka, Japan.

USGS, 2008. USGS Fact Sheet 2008-3049: Circum-Arctic Resource Appraisal: Estimates of Undiscovered Oil and Gas North of the Arctic Circle, U.S. Geological Survey, Reston.

Wright, B. and Timco, G., 1994. A review of ice forces and failure modes on the Molikpaq, Proceeding of the 12th International Symposium on Ice, Trondheim, pp. 816-824.

Yun, G. and Marsden, A., 2010. Methodology for estimating probability of success of Escape, Evacuation, and Rescue (EER) strategies for arctic offshore facilities. Cold Regions Science and Technology, 61(2-3): 107-115.

Zaki, R., 2015. Drilling waste minimization in the Barents Sea, UiT - The Arctic University of Norway, Tromsø.

Zhang, D. and Yue, Q., 2011. Major challenges of offshore platforms design for shallow water oil and gas field in moderate ice conditions. Ocean Engineering, 38(10): 1220-1224.

Zhou, L., Su, B., Riska, K. and Moan, T., 2012. Numerical simulation of moored structure station keeping in level ice. Cold Regions Science and Technology, 71(0): 54-66.

Zio, E., 2009. Reliability engineering: Old problems and new challenges. Reliability Engineering \& System Safety, 94(2): 125-141.

Zio, E., Baraldi, P. and Patelli, E., 2006. Assessment of the availability of an offshore installation by Monte Carlo simulation. International Journal of Pressure Vessels and Piping, 83(4): 312-320.

Zolotukhin, A. and Gavrilov, V., 2011. Russian Arctic Petroleum Resources: Challenges and Future Opportunities, Offshore Technology Conference, 7-9 February, Houston, Texas, USA.

Årthun, M., Bellerby, R.G.J., Omar, A.M. and Schrum, C., 2012. Spatiotemporal variability of air-sea $\mathrm{CO} 2$ fluxes in the Barents Sea, as determined from empirical relationships and modeled hydrography. Journal of Marine Systems, 9899(September): 40-50. 